\title{
EL CAMINO A LA GUERRA CIVIL. LA POLÍTICA DE ORDEN PÚBLICO EN EL TRIENIO DESDE LAS CORTES
}

\section{THE ROAD TO CIVIL WAR. PUBLIC ORDER POLICY IN THE TRIENNIUM FROM THE CORTES}

\author{
Manuel Martínez Sospedra \\ $\mathrm{UCH}-\mathrm{CEU}$
}

\begin{abstract}
SUMARIO: I. UN CONTEXTO DESFAVORABLE.- II. UNA CRISIS DE LEGITIMIDAD. APOYOS Y CARENCIAS.- III. UN SISTEMA FUNDADO EN LA CIUDADANÍA ORDENADA POR EL AYUNTAMIENTO CONSTITUCIONAL. VACÍOS INSTITUCIONALES Y PROBLEMAS DE APLICACIÓN.- IV. LA EVOLUCIÓN DE LA DISIDENCIA: DE LA CONSPIRACIÓN A LAS PARTIDAS.- V. LA EVOLUCIÓN DE LA POLÍTICA DE SEGURIDAD.- VI. EL FRACASO DE LA SUBVERSIÓN INTERNA Y LA INTERVENCIÓN.
\end{abstract}

Resumen: El restablecimiento del sistema constitucional doceañista en 1820 se insertó en un contexto hostil, tanto desde la perspectiva interna como desde la internacional. En el Trienio hubo una pronunciada problemática del orden público ligada a los problemas de bandidismo y a la presencia armada de la disidencia realista, la cual desencadena una "guerra de partidas", palpable como tal al menos desde fines de 1820. Esta intentó generar un Estado Absolutista alternativo en el interior capaz de batir militar y politicamente al Estado Liberal, cuyo resultado fue la primera de las guerras civiles del XIX: la insurrección realista de 1822. El intento fracasó porque el Estado liberal no fue suficientemente fuerte como para erradicar las partidas. Sin embargo, a pesar de la división de los constitucionales, sí consiguió evitar que se formara un ejército realista de estructura tradicional e impidió la aparición de "zonas liberadas" que pudieran servirle de base. Al final, la ruptura abierta entre el Rey y las Cortes (marzo de 1823) terminó con la ficción inaugurada en marzo de 1820: con este Rey no había monarquía constitucional posible sobre la que reposar tanto el sistema constitucional como la lealtad de las fuerzas armadas.

\begin{abstract}
The reestablishment of the doceañista constitutional system in 1820 was inserted in a hostile context, both from the internal and the international perspective. In the Triennium there was a pronounced public order problem linked to the problems of banditry and the armed presence of the royalist dissent, which triggered a "war of parties", palpable at least since the end of 1820 . This tried to generate an alternative absolutist State in the interior capable of defeating the liberal State militarily and politically, the result of which was the first of the 19th civil wars: the royalist insurrection of 1822 . The attempt failed because the liberal State was not strong enough to eradicate the parties. However, despite the division of the constitutional ones, it did manage to avoid the
\end{abstract}


formation of a royalist army with a traditional structure and prevented the appearance of "liberated zones" that could serve as its base. In the end, the open rupture between the King and the Cortes (March 1823) ended with the fiction inaugurated in March 1820: with this King there was no possible constitutional monarchy on which to rest both the constitutional system and the loyalty of the armed forces.

Palabras clave: Trienio Liberal, orden público, partidas realistas, guerra civil

Key words: Liberal Triennium, Public Order, Royalist Parties, Civil War

Este suceso, bastante por si solo para desacreditar nuestra gloriosa revolución, lo considero como el principio de hostilidades entre los ciudadanos, y el precursor cierto de una guerra civil en la que los españoles van a degollarse unos a otros con escándalo de la Europa y para caer otra vez en un despotismo espantoso.

DSC, Pacheco 9/5/1822, p. 1264.

\section{UN CONTEXTO DESFAVORABLE}

La restauración del régimen constitucional mediante la puesta de nuevo en vigor de la Constitución de 1812, en marzo de 1820, merced a la combinación entre un pronunciamiento militar y el colapso del gobierno personalista del rey (que no el Antiguo Régimen) se produce en un contexto nada favorable, ni en el orden interno ni en el orden externo. Por lo que toca al primero España lleva en guerras ininterrumpidamente desde 1804, en el curso de ese tiempo la monarquia ha perdido de facto la Armada, lo que, en un imperio pluricontinental, implica la extrema dificultad de controlar desde la metrópoli la América española, contando con un sistema fiscal muy deficiente, la Hacienda esta agotada y, además, fuertemente endeudada: no hay recursos, lo que explica la imposibilidad de acabar con la disidencia americana al extremo de que si las guerras de emancipación duraron catorce años ello se explica esencialmente por su naturaleza de guerra civil interamericana. Además la Guerra de la Independencia, desarrollada en el territorio peninsular, implicó seis años de guerra total en la que los contendientes vivieron esencialmente sobre el terreno, arruinando al país y provocando una fuerte erosión de su demografia. Adicionalmente la coyuntura económica postnapoleónica fue depresiva, cuanto menos hasta mediados de la década de 1820. Los años del Trienio no fueron de los mejores, ciertamente.

La reanudación de la revolución, que de eso se trata, iba a contracorriente de la tendencia dominante en la Europa de la Restauración. De las cinco potencias principales, tres ( Austria, Prusia y Rusia) eran defensoras vigorosas del absolutismo monárquico y radicalmente hostiles al constitucionalismo liberal (Austria destruyó los intentos piamontés y napolitano por la fuerza de las armas), la Francia de la Carta y la Inglaterra tory estaban firmemente comprometidas con el predominio social y político de la aristocracia y eran por ello contrarias a cualquier experimento político que de alguna manera estuviera relacionado con la revolución, aunque no eran partidarias ciegas del absolutismo (y aun menos de la práctica de gobierno fulanista del Fernando VII) no podían aceptar un modelo político que implicaba el desplazamiento del poder de la nobleza a la burguesía emergente, es más, en el caso francés, en el que la monarquía restaurada se 
sentía frágil, un sistema constitucional fundado en el odiado principio de la soberanía nacional en un país vecino era visto, no sin razón, como un riesgo inasumible ${ }^{1}$. En la primera mitad de la década de los veinte las revoluciones ibéricas se percibían como un cuerpo extraño a extirpar. Incluso en el caso más moderado, el británico, el gobierno de Su Majestad (sin cuya colaboración, cuanto menos pasiva, no hubiera sido posible el golpe absolutista de 1814) podría tal vez admitir alguna variante del constitucionalismo monárquico al estilo de la Constitución siciliana de 1812, imitación de las instituciones británicas, en tanto en cuanto un diseño asi podría garantizar la hegemonía de la aristocracia, como sucedia en la Gran Bretaña anterior al Reform Bill de 1832. Pero en modo alguno podía permitirse el lujo de que algunos de los principios que dieron lugar a la revolución y al imperio (que tanto costaron derrotar) hicieran pie en la Península. Para las principales potencias (y buena parte de las que no lo eran) el gobierno representativo podia ser bien una tradición, bien un mal necesario, pero en caso de aceptación aquel debia basarse en alguna variante del principio monárquico o, a lo sumo, en alguna clase de soberania parlamentaria al estilo británico: the King in Parliament ${ }^{2}$. Es claro que la Constitución de 1812 ni podía satisfacer la pretensión de predominio de la nobleza ni, mucho menos, las exigencias del principio monárquico.

En pocas palabras la revolución reanudada entraba en el escenario con un país agotado, una Hacienda exhausta, una economía estancada, si no en recesión, en un contexto europeo en el que no había amigos y el escenario estaba dominado por potencias con buenos motivos para ser hostiles a cualquier experimento político que portara el recuerdo de los años de la revolución y del imperio.

\section{UNA CRISIS DE LEGITIMIDAD. APOYOS Y CARENCIAS}

Para que un régimen pueda ser estable y duradero debe fundarse en un principio de legitimidad ampliamente mayoritario. Poco menos que por definición una revolución es un proceso político en el que se abandona un principio de legitimidad -el preexistente y propio del sistema politico que se abate- a favor de otro, el correspondiente al orden nuevo que se pretende establecer. En otras palabras, una revolución es un proceso necesariamente mercurial, porque comporta una crisis de legitimidad, y con ella, un desacuerdo sobre el justo título de mando ampliamente extendido. En nuestro caso la legitimidad propia de la monarquía patrimonial (el "rey por el derecho de mis padres" invocado por Carlos IV en mayo de 1808 ), y que es el supuesto implícito de la traslatio imperii de los tratados de Bayona entre el rey padre y el rey hijo, de un lado, y el emperador del

1 Significativamente la nota del gobierno galo remitida en enero de 1823 subraya que "E1 Gobierno del rey esta íntimamente unido con sus aliados en la firme voluntad de rechazar por todos los medios los principios y los movimientos revolucionarios". Diario de Sesiones de Cortes, 9/1/1823, p. 1294 (En adelante DSC). Los principios y los movimientos, mas claro imposible.

2 Recuérdese que fue la presión británica la que decidió la publicación de la Constitución siciliana de 1812, con su combinación de Cámara aristocrática y sufragio fuertemente restringido en concepto de modelo alternativo al constitucionalismo revolucionario, y que el Acta de Viena de 1815 permite a los estados parte de la Confederación germánica dotarse de constituciones escritas siempre que estas se basen en el principio monárquico. Tal vez el mejor ejemplo el texto bávaro de 1818 . 
otro, se rompe merced al doble fenómeno del rey por aclamación popular de Aranjuez, y la traslatio inválida tanto por falta de libertad, como por no haberse llevado a cabo en territorio del reino y ante las Cortes del mismo, como alegó en la primavera de 1808 alguien tan poco sospechoso de liberal como el Obispo de Orense. Una guerra de liberación frente al francés y el gobierno intruso solo podía ser una guerra popular y esta, velis nolis, implicaba una revolución política: si se cuenta con una estructura política que se puede definir como una monarquía compuesta y la pieza central, el rey, falla aquella se descompone (esa es la raíz última de la emancipación), y una recomposición popular solo es sostenible reclamando el rol central al populus que se alza: esa es la raíz del decreto de 20/9/1810 y su proclamación de la soberanía nacional. No sin razón el Toreno de la década de 1840 insiste en su Historia... en el carácter popular de la resistencia nacional.

Pero en 1810 el principio de soberanía nacional responde todavía a su diseño original: la nación es el conjunto de personas que viven bajo una misma ley y están representados en una misma legislatura, es, pues, la revolución liberal. El resultado es una fractura política que afecta al núcleo mismo de la obligación política: quien tiene derecho a mandar. La respuesta liberal y constitucional es clara: la nación de ciudadanos representada, de ahí el art.1 de la Constitución de 1812, empero esa no es la única respuesta posible y, desde luego, no es la única que cuenta con aceptación social, la soberanía nacional tiene que competir con quienes sostienen alguna variante de la soberanía compartida entre las Cortes y el rey (la cita obligada es la de Jovellanos), y la de aquellos otros que, al precio de la contradicción, sostienen la soberanía real y, con ella, un absolutismo más o menos templado. Una lectura detenida del Manifiesto de los Persas muestra la amalgama, no siempre incoherente, de esas posiciones, que definirán el magma del realismo: el rey y las Cortes pero con predominio de estas, el rey y las Cortes como pariguales, el rey con las Cortes pero por encima de las Cortes, en el extremo la defensa del "rey neto", con su denuncia de una Constitución que reduce a un rey a la condición de mero magistrado. En el centro siempre el rey soberano o cosoberano, nunca un magistrado por amplios que sean sus poderes, como los propios firmantes del Manifiesto reconocen explícitamente en el texto de 1812 se da.

Sobre ese diferendo de fondo se van a entrecruzar los conflictos de intereses que afectan al rol de la nobleza, a la posición del clero secular, a la cuestión del clero regular, y a los intereses de la burguesía y clase media urbana de un lado, y del campesinado del otro. El resultado es que todo planteamiento político es divisivo $\mathrm{y}$, al faltar el necesario acuerdo sobre la legitimidad, no puede haber estructura política mayoritariamente aceptada que canalice y regule la solución pacífica a dar a los conflictos en presencia. El problema surgido en 1808 no empezará a tener visos de solución hasta después de 1876.

La crisis de legitimidad tiene por efecto dejar sin campo de juego a una parte muy grande de la población. La diferencia sobre el justo título de mando entrega la arena politica a los militantes de las distintas fracciones políticas, y deja sin terreno de juego a la parte de la población, sin duda ampliamente mayoritaria, que carece de posición política definida y se torna objeto, y no sujeto, de la acción política: no hubo grandes protestas ante el pronunciamiento de 1814, el régimen fernandino cayó por desasistencia en febrero/marzo de 1820. Minorías de 
militantes disputan en el espacio político ante la pasividad, menguante, de la mayoría de la población.

El vacío generado por la crisis de legitimidad abre amplio campo a las relaciones de fuerzas directamente manifestadas. Por ende lo que cuerdamente llamó Toreno "guerra y revolución de España" tiene un efecto adicional: la guerra popular es una guerra fundamentalmente irregular, por emplear la terminología de la época es una "guerra de partidas", una guerra inorgánica que carece de la regularidad y previsibilidad propias del enfrentamiento entre tropas regulares en una guerra formal, una guerra en la que la diferencia civil/combatiente se difumina y, como consecuencia, se produce un recurso generalizado a la violencia, a una violencia que se vive como legítima y que, al rutinizarse, facilita su percepción como recurso político ordinario. No es casual el estereotipo de los viajeros románticos de mediados del XIX del campesino español montado en su mula con la carabina terciada sobre la silla. No es sólo, y no es principalmente, un problema de bandidismo, aunque ciertamente influye, y no poco, el hecho de que en no pocas ocasiones la frontera entre bandido y guerrillero, entre banda y partida, es muy porosa y se pasa fácilmente de un rol al otro, y viceversa ${ }^{3}$. Es, ante todo, la asunción de que el uso de la violencia es un instrumento político más, el recurso al cual se da por descontado cuando se estima necesario. Para quienes nos hemos beneficiado de la demonización de la violencia consecuencia directa de la última guerra civil $^{4}$ resulta dificil asumir que las cosas puedan funcionar de otro modo, pero pueden funcionar así, como acredita la popularidad de la copla carlista en la que se pedia a la esposa el fusil porque "voy a matar más guiris que flores tienen mayo y abril".

\section{UN SISTEMA FUNDADO EN LA CIUDADANÍA ORDENADA POR EL AYUNTAMIENTO CONSTITUCIONAL. VACÍOS INSTITUCIONALES Y PROBLEMAS DE APLICACIÓN.}

Como es común en las Constituciones de la "era de las revoluciones" el sistema diseñado en el texto de 1812 reposa sobre una definición muy amplia de la ciudadanía, que sitúa el sufragio al borde del sufragio universal, bien que moderado por la elección indirecta: solo los varones mayores de edad sin domicilio o en estado de sirviente doméstico, o quienes tienen ancestros marcados por la esclavitud negra quedan, en principio, fuera del proceso politico salvo concesión otorgada por las Cortes ${ }^{5}$. Se está aquí muy lejos de la diferenciación entre ciudadanos activos y pasivos de la Constitución gala de 1791

3 Ad exem vide en las Memorias de Alcalá Galiano la anécdota del cabecilla realista perseguido por el autor siendo intendente de Córdoba.

4 Según se cuente la cuarta o la quinta en menos de siglo y medio.

5 En la exclusión de los últimos desempeñó un rol fundamental la representación americana en las Cortes Generales y Extraordinarias: los criollos no quieren compartir el poder con las castas. No me parece ocioso señalar que Blanco White, si bien criticaba la discriminación por el estigma que suponía, proponía a los criollos como alternativa el sufragio censitario, a la postre la mayoría de los afectados no pertenecen a las clases selectas de la sociedad. Vid. M. Martínez Sospedra, "Pertenencia nacional, igualdad y representación. Los decretos de 15 de octubre de 1810 y 9 de febrero de 1811 sobre la representación americana en las Cortes", en P. Garcia Trobat y R. Sánchez Ferriz, El legado de las Cortes de Cádiz, Tirant lo Blanch, Valencia, 2011 pp. $529-$ 568. 
$\mathrm{y}$, por supuesto, del sufragio censitario, que entre nosotros tendrá que esperar a la reserva a los mayores contribuyentes de $1834^{6}$ o a la ley electoral de 1837 . Frente a los críticos británicos de tan amplio sufragio recordará Argüelles que en 1812 el país era "una democracia militar" y que, por ello, era ineludible que lo fuere política. Si hay que hacer caso a Caballero en la última ocasión en que el sistema se empleó (1836) tuvieron derecho de sufragio cerca de tres millones de electores, cifra que no se alcanzará hasta las elecciones del Sexenio y, después, hasta la llegada definitiva del sufragio universal masculino en 1890.

Sobre la base de una ciudadanía muy ampliamente definida el eje en torno al cual gira el sistema gaditano es el ayuntamiento constitucional, tal y como lo definieron la Constitución y la Instrucción de 1813. Su rol era tan fundamental que cuando se planteó en las Cortes Generales y Extraordinarias el problema de qué hacer con los pueblos americanos en los que toda o la mayoría de la población estaba integrada por castas y, por tanto, excluidas de la ciudadanía, los diputados constituyentes no tuvieron más remedio que autorizar en tales casos la constitución de ayuntamientos conforme a las reglas comunes, pues de otro modo se produciría nada menos que la aplicación territorial parcial del sistema constitucional, que no regiría en tales poblaciones ${ }^{7}$. No es de extrañar: el ayuntamiento constitucional dispone de los datos que permiten determinar quien es ciudadano y, por tanto, quien es elector y elegible, le corresponde el reparto de las contribuciones y al mismo compete la formación, equipamiento y mando directo de la Milicia Nacional. El voto, el dinero y el fusil. Sobre esa célula básica se erige la diputación provincial (una suerte de diputación foral vasca sin Junta General), y el gobierno nacional y sus delegados provinciales, los jefes políticos y los intendentes.

La administración general esta situada bajo la directa dependencia del rey y sus ministros, que cuentan con agentes en cada provincia, como se ha visto, agentes que integran la diputación provincial y pueden actuar tanto directamente como delegados del gobierno a través de su propio (y reducido) aparato administrativo, e indirectamente a través de la diputación, de la que forman parte junto con los electos y a la que presiden. Aunque técnicamente la diputación es una institución propia de la Administración del Estado, cuya función es enlazar al jefe politico y al intendente con los ayuntamientos con la finalidad primordial de la gestión de la Hacienda, al estar integrada mayoritariamente por electos resultaba políticamente inevitable que se desarrollara la propensión a considerar a la diputación como un cuerpo de representantes del electorado. Aquí la realidad arrinconó rápidamente el dogmatismo original, según el cual no hay más que un representante de la nación: las Cortes, los demás no son representantes sino funcionarios electos.

Una estructura así diseñada, máxime cuando apenas se está comenzando a desarrollar una administración estatal directa con presencia en todo el territorio ${ }^{8}$, depende en gran medida de la colaboración y apoyo de -al menos- las élites

${ }^{6} \mathrm{La}$ exposición que acompaña al Estatuto Real precisa "que el principio fundamental de nuestras antiguas Cortes había sido dar influjo en los asuntos claves del Estado a las clases y personas que tenían depositados grandes intereses en el patrimonio común de la sociedad".

7 M. Martínez Sospedra, Gobierno interior y Constitución, REFC, Valencia, 2013 pp. 337-64.

8 En el Trienio ese es un fenómeno incipiente, que sólo se desarrollará de modo significativo tras 1824 . 
locales, sin cuya colaboración la máquina inevitablemente tendría serios problemas de funcionamiento.

El resultado es una estructura administrativa que solo puede resultar funcional y eficaz en el supuesto de que una mayoría aplastante de la población politicamente activa acepte el sistema y/o acceda a colaborar en su funcionamiento. La ruptura entre el rey y el constitucionalismo operada en 1814, con las consecuencias inevitables que de ella se siguen, mina de raíz esa posibilidad. El resultado necesario es que cuando el sistema se pone en planta en la primavera de 1820 aparece a la luz pública que aquel supuesto implícito: la lealtad de los electos al sistema constitucional, no es siempre y necesariamente evidente $\mathrm{y}$, aun cuando mayoritariamente los realistas no concurren sistemáticamente a las elecciones, su presencia resulta inevitable, lo que fragiliza un sistema al que una parte de los electos y buena parte de la población entienden como carente de legitimidad.

En el ámbito de la seguridad pública el problema se plantea en términos especialmente agudos, tanto por lo que hay, cuanto por lo que no hay. En linea de principio es más importante lo segundo, aunque en la práctica aflore antes lo primero. El sistema constitucional no tiene previsión alguna dirigida a establecer una policía profesional que dé a las autoridades tanto información como capacidad de control de la población. Es más, no sólo esa viga falta en el edificio, es que la figura de la policía misma esta ligada directamente al recuerdo del gobierno intruso (art. 27 Estatuto de Bayona), y a la arbitrariedad con la que la policía josefina actuó durante la guerra, la policía se percibe en consecuencia como un instrumento propio de sistemas despóticos, incompatible con la libertad. ${ }^{9}$ Por eso no fue posible crearla durante el Trienio.

La segunda pieza ausente es la de una gendarmería o policía rural profesional. Nuevamente aparece aquí el espectro napoleónico: la gendarmería es un instrumento de opresión por las mismas razones que la policía y, adicionalmente, porque pone en cuestión, aunque sea indirectamente, la figura de la Milicia. Lo propiamente liberal, lo coherente con el sistema de libertad que la Constitución consagra, es que la tutela de la seguridad pública que a todos los ciudadanos afecta esté a cargo de los propios ciudadanos: la Milicia Nacional como autotutela de la seguridad y el orden público. Si pensamos en un escenario en el que no hay otra fuente de problemas de orden público que la delincuencia, el argumento puede ser plausible, pero cuando la fuente principal de aquellos no son los bandidos, sino los propios convecinos que apoyan a las partidas o, pero aún, se integran en ellas, cuando el enemigo del pueblo no es alguien ajeno, sino alguien próximo, la necesidad de una gendarmería que permita eludir el riesgo de la guerra vecinal y con ella asegure que la procura del orden público pueda obtenerse $\sin$ exponer directamente vida, familia y patrimonio, la carencia aparece con plena claridad, como veremos.

\footnotetext{
9 En el Antiguo Régimen hispano la Inquisición opera como un sucedáneo de la inexistente policía, toda vez que la española es una Inquisición subordinada desde su origen al poder real. Por eso se entiende, por ejemplo, que Hidalgo y Morelos fueren perseguidos y condenados por el Santo Oficio, o que fuere este el encargado de evitar la difusión de la Carta a los Españoles Americanos de Vizcardo. Y por eso cuando tras la caída del régimen constitucional el Santo Oficio no se restablece el régimen fernandino establece una policía profesional.
} 
Las carencias, lo que no hay, ponen de relieve los defectos del sistema diseñado: este es necesariamente muy costoso, porque implica la existencia sobre el mismo territorio y población de dos fuerzas militares: el Ejército y la Milicia, con el agravante de que ambas están llamadas a ser muy numerosas. Además, la Milicia esta pensada no tanto para asegurar la tranquilidad interior cuanto para operar como fuerza de apoyo del ejército en caso de guerra, como queda muy claro de la mera sistemática del T.VIII de la Constitución, y como corresponde a un cuerpo que se concibe originalmente como heredero de las milicias provinciales del Estado borbónico. Finalmente, la Milicia es vulnerable al conflicto político, y ello tanto si se plantea el mismo entre los constitucionales y sus enemigos, como si aquel surge del enfrentamiento en el seno de la familia liberal (cosa que aflorará a fines de 1821 con la insurrección de una parte de los exaltados andaluces frente al gobierno moderado, en Cádiz y Sevilla).

Para completar el cuadro hay que anotar que la Constitución es muy pobre en lo que afecta al Derecho de Excepción. Por de pronto la misma no contiene mas que previsiones puntuales, en la ley fundamental de Cádiz no hay nada similar a las posteriores regulaciones que contienen un programa detallado y graduable de la limitación temporal de la eficacia de los derechos constitucionales al efecto de restablecer una normalidad alterada. La Constitución de 1812 se limita a prever la posible detención gubernativa por razones de seguridad (art. 172.11.), de duración limitada a las 48 horas, transcurridas las cuales se debe poner a disposición del juez al puesto en custodia, a la regla del art. 290: la detención sólo puede durar 24 horas antes de la puesta a disposición del juez, la prevenida en el art. 306 sobre la inviolabilidad del domicilio, que se remite a la ley, y la que figura en el art. 308, que limita el derecho de excepción a la suspensión de las formalidades sobre los arrestos. Es cierto que el mantenimiento en vigor de al menos una parte de la Novísima, por más que en estos asuntos la regularidad constitucional de aquella no era precisamente evidente, podía funcionar como una solución transitoria, pero muy pocas herramientas más están a la disposición de quienes tienen que gobernar bajo una Constitución pensada para condiciones de normalidad, pero se encuentran con que esa normalidad no existe.

Adicionalmente, pese a la enérgica tutela de la unidad religiosa que consagra el texto constitucional, el programa liberal, con su propósito de acabar con las manos muertas y facilitar el ingreso en el mercado de la propiedad inmobiliaria congelada, ponía necesariamente al constitucionalismo en rumbo de colisión con la Iglesia católica española, en especial con el clero regular. Por ende, en el seno del clero se halla ampliamente difundida una visión apocaliptica de proyecto liberal, que se asocia con el desmantelamiento y escisión de la Iglesia primero y la persecución después, que operará en Francia entre 1790 y el concordato de 1802. Los constitucionales son percibidos como una amenaza existencial para la Iglesia, de lo que se siguen al menos dos clases distintas de consecuencias: de un lado en el Trienio no va a operar la identificación entre la causa nacional y la defensa de la fe, como en 1808, antes al contrario esta última se percibe, y es difundida como, incompatible con el sistema constitucional; del otro la mayoría de la Iglesia va a asociar la defensa de sus intereses con los de la monarquía absoluta: la "Alianza entre el Altar y el Trono", alianza que se disolverá tras 1833. Las consecuencias se verán con claridad entre abril y septiembre de 1823. 
Finalmente, tras su llegada al poder en marzo de 1820 los constitucionales heredan la máquina del Estado hasta entonces existente. De hecho, el detonante de la revolución trae causa de una sublevación militar. Por razones muy complejas, que no procede tratar aquí, el retorno de la Constitución se debe antes que nada al predominio liberal en el seno del ejército ${ }^{10}$. Mientras sea posible compaginar la lealtad al rey con la lealtad al sistema, el apoyo mayoritario en las Fuerzas Armadas se convierte en la viga maestra del edificio constitucional realmente existente, cuando la ficción del "rey constitucional" se hunda en 1823 el régimen caerá, pero significativamente el absolutismo posterior desconfiará de un ejército, aun purificado, y buscará la protección de su propia Milicia: los voluntarios realistas.

De otra parte, los constitucionales heredan una burocracia pública y una magistratura que, en esencia, son los del absolutismo fernandino. El problema es menor respecto de los empleados públicos, porque estos lo son en razón de la confianza de los gobernantes y estos disponen discrecionalmente de los puestos, esa plena disposición del empleo público permite el uso político del mismo y, por ello, permite nutrir de personal de confianza al aparato del Estado, al precio de cesantes y cesantías. No pertenece al reino de la casualidad que su sobreabundancia sea citada en las fuentes de la época como uno de los factores de descontento con el régimen constitucional. Distinto es el caso de la judicatura, aquí el propio sistema establece la inamovilidad, de tal modo que, en principio, los jueces del absolutismo se tornan jueces del sistema constitucional, empero la lealtad a este de buena parte de los miembros de aquella envenena las relaciones entre los constitucionales y la magistratura. No sin motivo: un sistema constitucional no puede sostenerse a largo plazo sin el sostén de jueces y funcionarios. Véase Weimar.

\section{LA EVOLUCIÓN DE LA DISIDENCIA: DE LA CONSPIRACIÓN A LAS PARTIDAS.}

Los primeros meses de vida del sistema constitucional son relativamente tranquilos, hasta finales del verano no aparecen signos claros y alarmantes de disidencia $^{11}$, en cambio desde el comienzo sí se aprecia la preocupación por el bandolerismo toda vez que el mismo puede ser usado para desacreditar el sistema constitucional ${ }^{12}$. Si bien no se oculta que en la raíz del fenómeno se halla en la combinación entre concentración de la propiedad, campesinado sin tierra y trabajo estacional. Ya desde el principio se señala una grave deficiencia de la estructura de los servicios de seguridad: la fuerza militar es insuficiente para combatir un problema muy extendido y se plantea la necesidad de crear policía profesional a partir de una sugerencia destinada a tener larga vida: la de crear de modo general unidades de miqueletes y miñones según el ejemplo vasco. ${ }^{13}$ No

10 Anota con cuidado Galdós: especialmente entre los cuerpos facultativos.

${ }^{11}$ Incidentes en Madrid. DSC, Legislatura de 1820 7/09/1820 p. 854 y ss., el gobierno apunta a la existencia de conspiraciones en Galicia (Junta Apostólica). Ibídem, p. 863.

12 Vid. proposición Martínez de la Rosa. DSC, Legislatura de 1820, 30/7/1820 p. 323 , observación de Calderón, p. 330.

13 Secretario de Gobernación de la Península. DSC, Legislatura de 1820, 30/7/1820, p. 329, en el mismo sentido propuesta del Jefe Político de Aragón (ídem 25/08 p. 652 o del diputado Priego (26/08 p. 668). 
obstante la primera prioridad es poner en planta la Milicia Nacional. Aunque se produce un surgimiento cuasi espontáneo de una Milicia voluntaria ya en abril de 1820 (D. 24/4/1820), una Milicia que comienza a aparecer como el brazo armado del liberalismo, es preciso acometer una regulación completa y general. El proyecto de reglamento de la Milicia se presenta el 4 de agosto ${ }^{14}$ y los términos en los que lo hace son bien claros: se trata de una "urgentísima necesidad de la Nación a la seguridad pública" en razón de que "siendo el objeto a que se dirige el establecimiento de esta clase de Milicia el auxiliar en la conservación del orden y la tranquilidad pública", unido a la necesidad de que la carga que la Milicia supone se distribuya con carácter general al efecto de "repartir una carga que en la actualidad pesa sobre una corta proporción".

La regulación que se establece, y que va a permanecer, declara obligatoria la pertenencia a la Milicia para todo ciudadano entre los 18 y los 50 años de edad, exceptuando tan sólo a los funcionarios públicos, los ordenados in sacris, el personal sanitario, los ciudadanos suspendidos de tal calidad y los jornaleros. Los mandos son de elección por y entre los milicianos y se dota a la Milicia de un régimen disciplinario menos riguroso que el de ordenanza ${ }^{15}$. Los milicianos sólo están sujetos a disciplina militar cuando se hallan de servicio. La Milicia esta subordinada a la autoridad politica local

Porque siendo una institución civil, bien se considere el objeto al que se dirige o bien a la clase de individuos que la componen, no está en el orden natural de las cosas que su mando pertenezca, por los menos en los casos ordinarios, a otra autoridad que la particularmente encargada de la conservación del orden público y la seguridad interna de los pueblos.

Con la consecuencia obvia: la Milicia esta preordenada a la persecución de los malhechores y la defensa de los pueblos.

Ahora bien, a partir del verano de 1820 comienza a hacer acto de presencia un tipo de alteración del orden y la seguridad públicos que excede la misión principal, comienza a hacer acto de presencia la combinación entre conspiradores y "facciosos" y, con ella, el problema de la discutible lealtad de al menos una parte de la judicatura al régimen constitucional. En fecha tan temprana como el 3 de enero de 1821 la Diputación Permanente recibe comunicación del jefe político de Zaragoza dando cuenta de una conspiración y de "la ninguna confianza que tiene en los jueces de primera instancia”.

El tiempo de tregua ha finalizado. La legislatura de 1821 va a ser mucho más agitada. Las Cortes de 1821 inician su andadura precisamente sobre la cuestión de la seguridad, ya el 5 de marzo se ve en la Diputación Permanente un escrito de varios diputados pidiendo se constituya una comisión que "informe sobre la seguridad pública y las medidas que convendría adoptar en el actual estado de la Nación". La materia vuelve a estar presente en las sesiones de la Diputación del 20 de marzo y del 4 de abril, el 7 de presenta un informe sobre "las maquinaciones de los enemigos del sistema", que se retira y, tras un intento de consensuar una política con el rey se entra en la dinámica de la militarización, de la que hablaremos. En el ínterin se afronta la primera manifestación ludita de nuestra historia: los sucesos de Alcoy. Aunque sobre ellos planea la sombra de la

${ }^{14}$ DSC, Legislatura de 1820 , p. 375 y ss.

15 Vid. DSC, Legislatura de 1820, pp. 223-4. 
conspiración 16 esta pronto se desvanece, los diputados valencianos que intervienen señalan la finalidad social de la actuación:

Una turba numerosa, compuesta de habitantes de varios pueblos de las inmediaciones de aquella villa, han incendiado y destruido algunas de las máquinas que adelantaban y facilitaban las manufacturas de lana. ${ }^{17}$

El hecho de que se trata fue un fenómeno de reacción frente a la revolución industrial, que cuenta con precedentes en Inglaterra:

Aquí se presenta un hecho muy semejante a los que no dejan de ser frecuentes en Inglaterra. Como la invención de las máquinas excusa gran multitud de brazos, nada tiene de extraño que viniendo a ser cesantes los que antes se ocupaban en el trabajo, acosados por el hambre y la necesidad se precipitan a estos excesos. ${ }^{18}$

Citándose la participación de jornaleros de pueblos del Valle de Albaida, Elche y la Vega Baja. A fin de articular una respuesta se forma una comisión, que presenta su dictamen el 18 de marzo, en el que señala que se trata simplemente de la oposición al maquinismo de "cardadores e hiladores", sin que exista en los sucesos indicios de "oposición al sistema". ${ }^{19}$ La posición que se adopta ante la crisis es simple: el gobierno constitucional "dejando libre la acción del interés individual, debe darle una protección sin limites, removiendo cuantos obstáculos la entorpezcan". En consecuencia, se acuerda otorgar a los industriales perjudicados una indemnización, bien entendido que se otorga en virtud "de un cálculo de economía política bien entendida" (Garelli). Eso sí, se rechaza la propuesta de Cortés de que la indemnización se destine a maquinaria porque ello "limita la libertad de industria"20.

Empero la cuestión social se deja de lado ante un fenómeno cada vez más extendido: las partidas son cada vez más numerosas y fuertes, de tal modo que comienzan a tener la capacidad de poner en tela de juicio la supremacía del Estado. La importancia del fenómeno en Castilla la Vieja ( donde opera el cura Merino) conduce a través de los oficios de los jefes políticos primero, y de la comparecencia del secretario de Gobernación de la Península después, a una iniciativa de Villanueva: que se cree una comisión que dictamine sobre una "enérgica medida que enfrene a los facciosos" al efecto de "evitar el peligro de guerra civil, que por tantas veces se ha intentado de diez meses a esta parte": que se establezca un procedimiento especial para reprimir los delitos contra la seguridad del Estado cuando se cuenta con una magistratura que sigue siendo la heredada del absolutismo y merece una confianza limitada ${ }^{21}$.

16 Toreno, 9/3/1821 p. 379 cuestiona si no se estaría "ante el principio tal vez del desarrollo de una contrarrevolución que nos amenaza"

17 Navarro, 9/3/1821 pp. 378-9.

$18 D S C, 9 / 3 / 21$ p. 379. Gisbert.

19 Vid. DSC, $18 / 3 / 1821$, pp. 543 y ss.

20 De hecho tanto Garelli como Toreno manifiestan que no se debe impedir que la indemnización se destine a adquirir fincas. El problema resurgirá el año siguiente, vid. DSC, Legislatura de 1822, 26/3/22, pp. 565 y s.

21 Vid. DSC, Legislatura de 1821, 5/4/1821, pp. 896 y ss. Nombramiento de la comisión p. 899. 
De la urgencia de la cuestión da idea que la mentada comisión presenta un proyecto de ley ad hoc tan solo cinco dias después, el 10 de abril ${ }^{22}$. El decreto propuesto se dirige directamente contra la disidencia politica realista:

Art.1. Son objeto de esta ley las causas que se formen por conspiración o por maquinaciones directas contra la Constitución, o contra la seguridad interior y exterior del estado, o contra la sagrada e inviolable persona del rey constitucional.

Las causas que se instruyan ingresan directamente en la jurisdicción militar:

Art.2. Los reos de estos delitos, cualquiera que sea su clase o graduación, siendo aprehendidos por alguna partida de tropa, así del ejército permanente como de la Milicia Nacional, destinada expresamente a su persecución por el Gobierno, o por los jefes militares comisionados al efecto por la competente autoridad, serán juzgados militarmente en el consejo de guerra ordinario de oficiales.

Las sentencias serán ejecutivas en términos similares a los previstos por la ordenanza:

... y sus sentencias se ejecutarán si las aprobase el capitán general con acuerdo de su asesor. Si la aprehensión se hiciese por orden, requerimiento o prestando servicio a la jurisdicción ordinaria, tocará a esta el conocimiento de la causa.

Es más, el sometimiento a la jurisdicción militar se dará incluso en el caso de los meros partícipes siempre que hagan resistencia a la fuerza

Art.3. También serán juzgados militarmente en la forma que expresa el artículo anterior, los que hagan resistencia con arma de fuego o blanca, o con cualquier instrumento ofensivo a la tropa, así del ejército permanente como de la Milicia Nacional, que los aprehendiere, aunque la aprehensión proceda de orden, requerimiento o auxilio prestado a las autoridades civiles.

Se presume que hay resistencia $y$, por ello, sometimiento a este procedimiento de excepción, en el caso de las personas que estén reunidas con los facciosos, aun cuando estas no cuenten con armas, así como las que fueren detenidas por la tropa huyendo tras haber estado con los facciosos y aquellos otros que hubieren estado en la facción y se encontraren ocultas fuera de su domicilio y armados.

Para que el sometimiento a esa justicia sumaria se dé basta que dicte el bando correspondiente (art.4). La competencia para enjuiciar militarmente corresponde a los oficiales que manden la tropa, empero si en lugar del ejército regular la represión es efectuada por la Milicia son los oficiales de esta los que están llamados a formar el consejo de guerra ${ }^{23}$.

En los demás casos la competencia corresponde a los tribunales civiles, pero estos deben seguir un procedimiento sumario: el promotor fiscal tiene tres dias

\footnotetext{
22 Vid. DSC, Legislatura de 1821, 10/4/21, pp. 993 y ss.

23 Conforme la Milicia se vaya convirtiendo en el brazo armado de los constitucionales la regla señalada supone entregar el juicio y condena de unos militantes politicos a una corte integrada por los militantes políticos adversarios.
} 
para acusar, el acusado 24 horas para designar letrado, el fiscal otras 24 para fijar la lista de testigos, el juez convoca vista a la mayor brevedad y dicta sentencia en tres dias. En todo caso la sentencia es ejecutoria: si fuere de absolución se procede a la inmediata puesta en libertad, si fuere de pena capital se ejecuta en 48 horas, las demás a la mayor brevedad.

No obstante la radicalidad del proyecto, cuya compatibilidad con la Constitución no es precisamente evidente, tal y como apuntó Cañedo ${ }^{24}$ la recepción del mismo por las Cortes suscitó un fuerte debate mayoritariamente orientado a endurecerlo. Para los constitucionales la disidencia realista habia sido tratada con moderación, sin que ello indujera a actitud correspondiente por parte de los realistas:

Grande sentimiento es para las Cortes verse precisadas a formar esta ley después de la moderación que se ha usado por espacio de un año con los que han cometido tales insultos contra el sistema; sin embargo, la necesidad exige y autoriza estas medidas ${ }^{25}$.

El tiempo de la indulgencia ha pasado, Martínez de la Rosa (no precisamente un radical) lo dice con claridad:

Ya tanta que tanta indulgencia alienta a los malvados; ya que ha transcurrido mas de un año desde nuestra restauración politica, y aun osan los enemigos de nuestra libertad minarla en sus mismos cimientos; cuando ha llegado el punto en que aparecen confundidos la moderación con la flaqueza ¿quién será el que nos culpe de que hostigados por los mismos perturbadores del orden, y después de haber tentado en vano los medios más suaves, tratemos ya de confundir sus esfuerzos y refrenar su osadía... ${ }^{26}$

Y agrega:

El que rompe descaradamente todos los vínculos sociales, el que resiste con la fuerza y desconoce el imperio de las leyes, ¿podrá quejarse, por ventura, de que se le juzgue militarmente, cuando es un enemigo público del Estado, semejante a un pirata o a un tránsfuga aprehendido entre las filas enemigas?27

Es más, la tendencia general es precisamente a ampliar la jurisdicción militar cuando pueda estimarse que aun no habiendo una resistencia de facto quepa hablar de resistencia implicita:

Partiendo de este principio, la comisión ha creído que cuando una partida de tropa va en persecución de gentes que se hallan reunidas para atacar el sistema, hay en este hecho una resistencia implícita, y por ello sus autores y cómplices quedan sujetos a la jurisdicción militar ${ }^{28}$.

O, según sostiene Cano Manuel:

${ }^{24}$ Cañedo, DSC, Legislatura de 1821, 15/4/1821, pp. 1064-66.

25 Giraldo, DSC, 15/4/21, p. 1071.

${ }^{26}$ Martinez de la Rosa, DSC, loc. cit., p. 1068.

27 Martínez de la Rosa, loc. cit., p. 1069.

28 Giraldo, loc. cit., p. 1072. 
En el art.5 se dice que siempre que la fuerza militar aprehenda algunos facciosos, prestando auxilio o de orden del gobierno político ya se supone que hay resistencia, y por consiguiente deben ser juzgados por la tropa ${ }^{29}$.

Y no bastando agrega:

Parece que cuando se prende a una porción de facciosos sin armas no puede haber hecho resistencia. Es cierto que no la harán a la milicia; pero es indudable que la han hecho a la autoridad pública no cumpliendo lo que les ha mandado, que es título bastante para que la autoridad civil, empleando la fuerza militar en la persecución de estos facciosos cuando no la han obedecido, los sujete a juicio militar sin introducir regla nueva ${ }^{30}$.

Por su parte Calatrava agrega que basta ser aprehendido por la columna, aun sin necesidad de haber ofrecido resistencia, para ser incluido en la competencia de la justicia militar:

Supongamos que el Gobierno autoriza a los comandantes y capitanes generales de las provincias para que envien columnas volantes que aseguren la tranquilidad pública; todos los que aprehendan estas columnas están sujetos a la jurisdicción militar ${ }^{31}$.

En tanto que para Romero Alpuente basta el bando para ello:

Mas luego de publicado el bando y llegado probablemente a su noticia, entonces, siguiendo la facción, aunque no haya resistencia, precisamente ha de ir a la jurisdicción militar ${ }^{32}$.

Los constitucionales son conscientes que el surgimiento y continuidad de las partidas son posibles porque cuentan con una amplia base social, para ellos es claro que la mayoría de la población rural no es favorable a la causa constitucional, pero se limitan a considerar que dicho fenómeno se debe a la hostilidad sistemática de la mayor parte del clero, así Cano Manuel:

Examinamos una clase de delitos, en los cuales conocemos que la influencia de cierta clase del pueblo español es la causa de su perpetración. ¿No se oyó decir aquí días pasados que los eclesiásticos y curas decían a sus feligreses que si no eran enemigos del sistema constitucional no les darian las cédulas del cumplimiento de la iglesia? ¿Qué extraño será que un pueblo tan sencillo como el español corra a alistarse en estas partidas, como en otros tiempos a las de Cruzada? ${ }^{33}$

Dicho influjo obliga a adoptar medidas que disuadan el auxilio a la rebelión, por ello se llega a proponer que el aforamiento ante la jurisdicción militar no se limite a los alzados, sino que se extienda a todos aquellos que, teniendo conocimiento del bando emitido por la autoridad pública, persistan en alguna clase de apoyo a la disidencia armada:

29 Cano Manuel, loc. cit., p. 1073.

30 Ibídem.

${ }^{31}$ Calatrava, loc. cit., p. 1075.

32 Romero Alpuente, loc. cit., p. 1079.

33 Cano Manuel, loc. cit., p. 1082. 
...y la comisión ha creído por el carácter del negocio de que se trata, que debía entrar en el espíritu de esta ley, y que debía calificar de resistencia, no solamente aquella que se hace en el campo contra una autoridad pública, sino aquella que se hace por desobedecer a la autoridad pública después de publicado un bando; y conociendo que tiene un motivo de influjo en cierto modo en el ánimo de todos los españoles, ha creído que debía presentar este gran freno para que retirándose a sus casas y abandonando la reunión, no llegue el caso de quedar sujetos a la jurisdicción militar ${ }^{34}$.

Visto lo cual se acuerda que el proyecto vuelva a la comisión al efecto de incorporar al menos algunas de las modificaciones sugeridas. El 16 de abril la Diputación Permanente recibe comunicación de la interrupción de la comunicación con Francia, obra de Merino, contra el que se movilizan no solo la fuerza regular, sino también a Juan Martín Díaz y a la Milicia. Como hay urgencia el nuevo dictamen de aquella se presenta el 17 de abril ${ }^{35}$. La nueva redacción especifica que la nueva regulación se aplicará no sólo a las partidas realistas y sus apoyos, sino también al bandolerismo ordinario (sin duda porque la divisoria entre banda y partida es con frecuencia porosa), que la resistencia que produce el aforamiento se extiende, más allá de la que se ofrece al ejército y a la milicia voluntaria, también a la ofrecida a la milicia local, que quienes se hubieren unido a las partidas antes de conocer el bando y conocido este se retiraren quedan exentos de responsabilidad (se consideran indultados), siempre que no hubieren sido conspiradores, que aforamiento y responsabilidad se extienden no sólo a los partícipes directos, sino también a los cómplices, que el deber de proclamar el bando que compete a la autoridad local no exime a esta de la obligación de dispersar a los comprometidos y prenderlos y que, en el caso de que la sentencia del consejo de guerra no fuere aprobada por el capitán general la causa pasaría al tribunal supremo de guerra y marina que decidiría en el término de tres dias.

Publicada la ley el 20 de abril se produce, pues, una militarización prácticamente completa de la lucha contra conspiradores y alzados, si bien en la práctica la carencia de un sistema eficiente de información (no hay policía) conduce a una aplicación casi exclusiva a partidas y partidarios. Es de notar la aparición progresiva de un lenguaje orientado a la descalificación ética de la disidencia política, tendencia que se acentuará en lo sucesivo: los realistas son perjuros, siniestros, malvados, etc., no son, pues una oposición leal, intrasistema, constituyen un oposición al sistema mismo y, como este es benéfico y está orientado a la procura de la felicidad de los españoles y a asegurar su libertad, la oposición a aquel deviene éticamente inadmisible, la oposición al sistema es un síndrome del mal. Lo que no es sino una imagen especular de la condena realista a los liberales como enemigos de Dios, la Religión y el Trono. La dialéctica amigo/enemigo se enseñorea del espacio público.

Entre tanto el 22 de abril la Diputación Permanente toma conocimiento de los sucesos de Salvatierra: se produce una insurrección popular, se cesa al ayuntamiento constitucional, se erige una "autoridad facciosa" que dirige la Milicia local, y se produce un enfrentamiento con el ejército. La institución básica

34 Cano Manuel, loc. cit., p. 1082.

35 Vid. DSC, Legislatura de 1821, 17/4/1821, p. 1108. 
del sistema es manipulada por sus adversarios para subvertir el régimen constitucional.

\section{LA EVOLUCIÓN DE LA POLÍTICA DE SEGURIDAD}

Apenas aprobado el decreto de militarización de la política de seguridad se suscita la cuestión del apoyo del clero a las partidas. El 26 de abril el Congreso recibe los partes del ayuntamiento de Vitoria y del jefe politico sobre las partidas que, de acuerdo con aquellos, reciben el apoyo de "la inmensa mayoría del clero" 36 . Como consecuencia se acuerda crear una comisión al efecto. El dictamen de esta ${ }^{37}$ aprecia la difusión de las partidas en las diócesis de Ávila, Osma, Burgos y Calahorra, constata que en todos los casos hay apoyo del bajo clero en tanto que los ordinarios se caracterizan por su pasividad. Al efecto de corregir esa situación se viene a proponer que se exija a los obispos que adopten las medidas adecuadas para corregir la situación señalada, que procedan a retirar las licencias para predicar y confesar a los clérigos desafectos y que las vacantes se cubran con regulares secularizados, de los que se presume adhesión al sistema. A la postre se dice en el debate que el clero secular es pagado con fondos públicos $\mathrm{y}$, por ello, su posición es semejante a la propia de los cesantes. Quiroga lo dice con rotundidad: hay que depurar.

Yo creo que deben tenerla, porque gravitan sobre el Estado y se hallan en caso de los empleados cesantes. Además, si estos hombres se ponen en los curatos, propagarán las ideas liberales, y serán más útiles que una porción de clérigos y aprendices de clérigos que tenemos y no necesitamos. ${ }^{38}$

En tanto que García Page, asimilando cuerpo nacional y constitucionalismo, como reclama la concepción revolucionaria de la nación, sostiene que el clérigo hostil a la Constitución debe ser cesado:

porque siendo una de las causas o motivos económicos para no ordenar o dar licencias el tener mala nota, no se me podía pasar por la imaginación que uso tiene la muy mala de ser enemigo de su Patria, pues todo el que es desafecto a sus leyes fundamentales lo es, fuese digno de ejercer tan sagrado ministerio. 39

La propuesta de la comisión no acaba de contentar a los exaltados, así Calatrava propone que vista la actitud de los obispos se obre la suspensión de licencias directamente por la autoridad civil, e invoca para ello el decreto de las Cortes generales y extraordinarias acerca de la suspensión de empleo a los reacios a cumplir los decretos de las Cortes, en lo que recibe el apoyo de Muñoz Torrero ${ }^{40}$.

Como la situación lejos de mejorar se deteriora, a principios de mayo Toreno propone la declaración del estado de sitio como medio de reforzar la militarización:

36 Vid. DSC, Legislatura de 1821, 24/4/1821, p. 1267.

37 Vid. DSC, Legislatura de 1821, 29/4/1821, p. 1326.

38 Quiroga, DSC, loc. cit., p.1329.

39 DSC, loc. cit., p.1330.

40 Vid. loc, cit., pp. 1331 a 1333. 
Poner en estado de bloqueo un distrito es dar al comandante militar de la partida o ejército que haya en el las facultades que tiene el gobernador de una plaza sitiada. ${ }^{41}$

Tras un debate en el que ocupa un lugar central la actividad guerrillera del cura Merino, la propuesta pasa a comisión. El dictamen de esta se presenta el último día de mayo y viene a asumir el fondo de la propuesta:

1. Que se autorice al gobierno para que en los casos en se estime conveniente remita a los capitanes generales y jefes militares destinados a perseguir a las facciones en los territorios que sean teatro de las operaciones militares, con plenitud de facultades que en general tiene en campaña con arreglo a la ordenanza. ${ }^{42}$

Al día siguiente aumenta la presión: a petición de Giraldo se leen los oficios acerca de la actividad partisana del cura Merino, que con una partida reducida (160 efectivos) opera en Burgos, lectura que conmociona a las Cortes cuando estas tienen conocimiento del fusilamiento de soldados rendidos por parte de la partida, la lucha se embrutece. El debate registra la conciencia de que la actividad de las partidas es posible porque los facciosos tienen "la devoción y el ánimo y la voluntad de los habitantes del país que ha escogido para teatro de sus operaciones" (Giraldo), en tanto que Palarea y Sancho (sin duda autoridades en la materia) señalan que el cura insurgente cuenta con "los justicias de los pueblos" que le dan cobijo e información sobre los movimientos de la tropa. Al avecinarse la clausura de las Cortes la cuestión se defiere a las Cortes Extraordinarias cuya convocatoria se pide al rey a la vista de la combinación de la insurgencia interna y la presión exterior. ${ }^{43}$

El factor exterior está llamado a incrementar su importancia porque pronto excede de la presión politica y diplomática. Con motivo de la extensión de la epidemia de fiebre amarilla a buena parte de Cataluña el gobierno francés establece un cordón militar en los departamentos próximos a la frontera pirenaica. Un "ejército de observación" cuyos efectivos se ven lenta pero constantemente incrementados. La existencia de ese ejército viene asociada a la tolerancia con la que las autoridades galas contemplan la presencia y actividades de personalidades realistas en el mediodia francés, en especial en la parte occidental de la cadena pirenaica. El horizonte exterior es cada vez más preocupante.

El segundo semestre del año 21 parece más tranquilo, visto desde las Cortes. Fuera de tomar nota de incidentes singulares ${ }^{44}$ la Cámara atiende esencialmente por lo que nos afecta al proyecto de organización de la Milicia Nacional activa ${ }^{45}$, en cuyo debate aparece tangencialmente la sombra de una intervención militar francesa, toda vez que la misma comportaría un incremento de la necesidad de la fuerza armada ${ }^{46}$, en especial dado el bajo nivel de efectivos del ejército y la virtual

\footnotetext{
41 Toreno, DSC, Legislatura de 1821, 2/5/1821, p. 1398.

42 DSC, Legislatura de 1821, 31/5/1821, p. 1973.

43 DSC, Legislatura de 1821, 25/6/1821, pp. 2512-13.

44 DSC, DP, 21/08/1821, 7/09/1821.

45 Presentado en 29/09/1821, p. 33. Dictamen 17/10/1821, p. 276.

46 DSC, 22/10/1821, pp. 343 y s.
} 
ausencia de marina ${ }^{47}$. En todo caso el gobierno tiene plena confianza en el ejército, cosa que los hechos justifican, porque, como señala Sancho:

Todos los políticos presentan a los ejércitos permanentes como enemigos de la libertad; pero el de España es su principal apoyo. ${ }^{48}$

Con todo, la necesidad de efectivos es perentoria y, en razón de ello, el 7 de octubre el secretario de Guerra oficia a las Cortes que es necesario ampliar el permiso dado el 24 de mayo para emplear a las unidades de la Milicia fuera de provincia en razón de la necesidad de establecer cordones sanitarios por epidemia de fiebre amarilla. ${ }^{49}$

Bruscamente la división de los liberales viene a agravar el problema: en noviembre y diciembre el Diario de Sesiones se hace eco de disturbios en Zaragoza y Alcañiz y, sobre todo, de la intentona exaltada de Sevilla y Cádiz, que provoca al menos dos reuniones de la Diputación Permanente y el Gobierno (9 y 12 de noviembre) así como la elevación de un memorial al rey sobre los sucesos de Andalucía y la general quiebra del orden público (3 de diciembre). Casi al mismo tiempo amaga el peligro realista: la DP recibe el 14 de diciembre noticia de los sucesos de Sangüesa y el 19 el informe del jefe politico sobre los de Pamplona, una insurrección en toda regla cuya importancia no se puede desconocer.

En sustancia lo sucedido en Pamplona se resume del siguiente modo: tras una campaña de agitación basada en la reclamación de la continuidad de los fueros, dirigida por una llamada "Junta restauradora de los fueros de Navarra", una organización clandestina provoca el levantamiento de la mayor parte de la Milicia Nacional de Pamplona50, el levantamiento fracasa por la intervención de la guarnición y la huida de los sublevados (descolgándose de la muralla, se agrega con cierta malicia). La cuestión es qué hacer. Las Cortes se debaten entre seguir el precedente de Salvatierra, esto es encausar a los mandos e indultar a los milicianos, o adoptar una resolución más severa. La cuestión trasciende el caso porque obliga a las Cortes a considerar la politica a seguir en aquellos casos en los que los órganos locales de gobierno, y la milicia que de ellos depende, no sólo no operan como un medio de defensa del sistema, sino que facilitan a sus enemigos los medios para derribarlo. Los milicianos pamploneses ¿deben ser

47 De hecho a finales de 1822 y primeros de 1823 el gobierno y las Cortes tratan de poner remedio a una situación muy seria, decretando primero la ampliación de efectivos del ejército en algo menos de 30.000 soldados, y votando después se adquieran material y buques en el exterior dada la pobre situación de los arsenales. Aunque se trata de una impresión provisionalísima todo parece indicar que la fuerza militar efectiva a fines de 1822 y principios de 1823 no debía exceder de los sesenta mil hombres, como mucho, estando estos dedicados a trabajos de guarnición y a la guerra civil. Lo que debe tenerse en cuenta al efecto de entender el comportamiento de los mandos del ejército a partir de abril de 1823 cuando la intervención se hace efectiva.

48 Sancho, DSC, Legislatura 1821/1822, 22/10/1821, p. 346. Hay que anotar que el cuerpo de oficiales esta en su mayoria a favor de la causa del rey constitucional. Mientras ese duetto aparezca como viable el ejército respaldará al régimen: se puede ser leal simultáneamente a la Constitución y al rey, cuando eso deja de ser posible (como tarde en marzo de 1823, asunto del traslado del rey y del gobierno a Sevilla) ese apoyo muy mayoritario quebrará, y lo hará en beneficio de la monarquía. De ahí el comportamiento de la fuerza armada ante la invasión.

49 DSC, Legislatura 1821/1822, 7/10/1821, p. 150, autorización acordada el día 9 p. 169.

50 "Se trató de extracción del espíritu público so color de comparaciones injustas entre las libertades de los antiguos fueros y las que la Constitución concede”. DSC, Legislatura 1821/1822, 22/01/1822. Dictamen de la comisión sobre los sucesos de Pamplona p. 1963. 
tratados como "cuadrillas de facciosos"?, y ya sabemos lo que eso significa. Una resolución rigurosa parece impolitica, pero la lenidad también lo es. La cuestión no se plantea al efecto de revisar el Decreto de 20 de abril, se plantea en términos de oportunidad politica:

Los hombres que una vez han vuelto las armas contra la Patria son traidores a la Nación; solo la humanidad de las Cortes puede indultarlos iy ojalá no tengamos que arrepentirnos! ${ }^{51}$

La razón nos la da Calatrava: en el caso de Salvatierra indultamos a clases y milicianos y los amnistiados se han tornado a sublevar ${ }^{52}$. El debate, a más de acreditar la identificación de la patria con la nación, y la de esta con el régimen constitucional (que es lo que se sigue de la concepción originaria de la Nación, esto es la revolucionaria) pone de relieve las dificultades de establecer un sistema político "popular" ( por emplear la expresión de Toreno) cuando una buena parte de ese pueblo le es refractaria. El debate es también interesante porque por primera vez se admite expresamente en las Cortes que el comportamiento de los milicianos leales no es siempre el que debería ser ${ }^{53}$. La sombra de los odios y querellas entre vecinos, siempre presente en una guerra civil, hace su aparición solemne en la escena. La resolución final, que se constituirá en el precedente a seguir para casos similares, será más rigurosa que en el antecedente de Salvatierra: se enjuiciará (y condenará, se supone) a los mandos y a la clase de tropa y la gracia solo se concederá a los milicianos rasos. ${ }^{54}$

La legislatura se cierra, por lo que aquí interesa por la discusión acerca de los sucesos de Madrid del 4 y 5 de febrero, con insultos a los diputados y el allanamiento del domicilio de algunos de ellos, en una operación política en la que se apunta a la coincidencia entre exaltados y realistas. Calatrava es claro:

Hoy no lo podemos dudar, hay una fracción liberticida; una fracción liberticida, digo, que, afectando amor a la constitución, y sirviendo acaso por el influjo extranjero de instrumentos a los mayores enemigos del sistema constitucional, no trata sino de impedir a esta infeliz Patria de la libertad que apenas principia a disfrutar. ${ }^{55}$

Las nuevas Cortes, ahora con mayoría exaltada, aunque la consistencia de la mayoria no era precisamente evidente, como pone de relieve en sus memorias Alcalá Galiano, tienen que hacerse cargo del país en un momento en el que ha venido a producirse algo muy parecido a una insurrección casi general, que irá

51 Quiroga, DSC, loc. cit., p. 1967.

52 Calatrava, loc. cit., p. 1969.

53 “...que en ciertos pueblos hay excesos de patriotismo por algunos que con el nombre de milicianos nacionales no se comportan tan bien como los milicianos de la ley". González Allende, loc. cit., p.1965. Conviene recordar que en un contexto de pobreza generalizada las partidas tienen que nutrirse de los recursos que arrebatan a los campesinos, pero que los milicianos se ven con frecuencia en situación similar dada la incapacidad propia y de las administraciones para proporcionar equipos completos y sostenimiento cuando los milicianos están en operaciones. En un contexto así los abusos están servidos.

54 DSC, Legislatura 1821/1822, 25/01/1822, p. 1995.

55 La discusión en $D S C$, Legislatura 1821/1822, 5/2/1822, pp. 2160 y ss. la cita de Calatrava, p. 2165. 
creciendo a lo largo del año, dando lugar a la primera guerra civil del s. XIX: la insurrección realista de 1822. La novedad no radica en que ahora haya conspiradores, partidas, ajustes de cuentas y conflictos entre fracciones liberales, la novedad radica en que el recurso a la violencia como instrumento político ordinario se torna habitual, en que ese uso pone en cuestión de modo muy amplio y efectivo la supremacía del Estado, en que este pierde de facto el control de partes amplias del territorio, y en el que se va a registrar el intento de erigir frente al Estado (constitucional) otro Estado (realista) cuyo símbolo más gráfico es la Regencia de la Seo de Urgell.

Una mirada al índice del Diario de Sesiones de la legislatura de 1822 pone de relieve el salto cualitativo que se está produciendo: la voz "facciosos" pasa de una referencia en la legislatura anterior a contar con 31 entradas, la voz "orden público" que no figura en el índice correspondiente a la legislatura extraordinaria $1821 / 22$ pasa a 32 entradas, en tanto que de dos comunicaciones del Secretario del Despacho de la Gobernación de la Península en la extraordinaria se pasa a 14 sobre orden público en la ordinaria de 1822. Para un plazo que va de marzo a junio no está mal. De hecho apenas se han abierto las Cortes Gómez Becerra presenta una proposición para que se cree "una comisión especial de tranquilidad pública", que se admite sobre la marcha ${ }^{56}$. El debate a que da lugar no tiene desperdicio, la situación es gravísima:

Nadie puede dudar que la tranquilidad pública peligra, no solo en el suelo que pisamos, sino también en todos los ángulos de la Monarquía

Y agrega:

Por todas partes se mueven pasos que tienden, en mi concepto, a la destrucción de la libertad; si no recorránse las provincias y se verá como se han manifestado enemigos de ella en Navarra, en Castilla la Vieja, en la Mancha, en las cercanías de Madrid, en Valencia, en Cataluña, en Aragón, y, en suma, en todas partes. ${ }^{57}$

No debe extrañar que los oradores recurran una y otra vez a la metáfora: caminamos sobre un volcán. Si se considera que en el debate se mencionan casos en los que los soldados que cantan una "canción patriótica" se ven insultados por el pueblo, quedan expuestos a ser asesinados al extremo de tener que recurrir a cargar las armas para defenderse ${ }^{58}$, o que

este estado de fermentación que hace que en los pueblos no se cumplan las leyes, que ha paralizado casi completamente la marcha del sistema constitucional en algunas provincias. ${ }^{59}$

No obstante el tiempo del consenso liberal aun no ha llegado, la comisión propone una suerte de supervisión general de la politica de orden público que los moderados rechazan porque perciben en ella el peligro de una deriva convencional, en consecuencia se acuerda no haber lugar a la votación.

\footnotetext{
56 DSC, Legislatura de 1822, 2/3/1822, p. 60.

57 Ibidem, pp. 60-61.

58 Ad exem. Saenz de Buruaga, loc. cit., p. 64.

59 Seoane, loc. cit., p. 61.
} 
La cuestión se retoma el día 9 de marzo donde se da cuenta de los sucesos de Barcelona (conflicto de autoridades sobre el mando directo de la Milicia) y de Murcia (jueces sospechosos de desafección, en especial uno por haber sido alcalde mayor con Elío en Valencia), dando paso a la comparecencia del ministro del ramo: todos los jefes politicos que tienen regimientos de Milicias piden al Gobierno que se mantengan sobre las armas ${ }^{60}$. La comparecencia da lugar a intervenciones parlamentarias sobre casos. Así Saavedra:

Solamente con extender la vista por la Península se verá que en casi todas las provincias hay una o dos ciudades, o algunos pueblos de consideración, notables por su desafecto al sistema constitucional, y que son centro de los mayores desórdenes y abrigo de los malvados. Testigos de esta verdad son Ciudad Real y Miguelturra en la Mancha, Lucena en Córdoba, Morella, Elche y Orihuela en Valencia, Orense en Galicia y Cervera en Cataluña.

Finalizando,

...y como no hay concurrencia pública en la que no grite la multitud alucinada: "vivan los cristianos, viva la Virgen y muera la libertad". ${ }^{61}$

En tanto que Rico expone las hazañas de Jaime el Barbudo en la Vega Baja del Segura secuestrando liberales en Orihuela ${ }^{62}$ o López del Baño expone el caso de Lucena: una "facción aristocrática" vence en las elecciones municipales y usa del poder local para impedir la puesta en marcha del sistema. ${ }^{63}$ Con todo, los más acertados: Munárriz: es necesaria la policía y Seoane: la división liberal es dañosa:

Yo estoy intimamente persuadido de que mientras no reine la más estrecha unión entre los hombres de bien, no podrá tenerse garantizada y segura la tranquilidad pública. ${ }^{64}$

Nótese: "los hombres de bien" y "los malvados", la sectarización de la política no afecta sólo a los realistas.

La cuestión sigue dominando el panorama político durante toda la primera mitad del año. Así el 18 de marzo se da cuenta de los sucesos de Madrid, en los que un grupo de soldados vitorea al rey absoluto, lo que comienza a parecer como parte de un plan concertado para minar un ejército que se sabe mayoritariamente liberal:

No sucede solamente en Madrid, sucede casi a la vez en todas las provincias; y se ve también que esto es un plan muy combinado, que la junta suprema de conspiradores trabaja incesantemente, y que se están minando los cimientos de la libertad65.

\footnotetext{
60 DSC, Legislatura de 1822, 9/3/1822, p. 270.

61 DSC, loc. cit., pp. 270-71.

62 DSC, loc. cit., p. 272, no es exclusivo, problemas similares en Sevilla pp. 272-73.

63 DSC, loc. cit., pp. 274-75 la solución propuesta: invalidar la elección al efecto de contar con un ayuntamiento liberal porque si no las instituciones no funcionan.

64 DSC, loc. cit., p. 276.

65 DSC, Legislatura de 1822, 18/3/1822 Castejón, p. 296, en el mismo sentido Seoane, p. 297.
} 
Lo que da lugar al acuerdo de crear una comisión ad hoc. Aun no se han apagado las voces cuando entran en escena los sucesos de Valencia: un grupo de soldados del $2^{\circ}$ regimiento de artilleria (Beltrán de Lis apunta: antiguos miñones de Elío) ataca una manifestación exaltada. La crisis, agravada por el choque entre el gobierno moderado y los exaltados, obedece, a juicio del ministro del ramo, a la misma finalidad:

Así, al mirar este exceso de Valencia, no puede el Gobierno considerarlo como un suceso tan aislado; lo mira, por los datos que tiene, como un suceso unido y relacionado con nuevas tentativas de un plan para introducir la desunión entre la fuerza armada y el pueblo, entre unos cuerpos del ejército y otros, entre el ejército permanente y la Milicia Nacional. Solo la unión puede salvarnos; y se trata de provocar la discordia. ${ }^{66}$

Vista la acumulación de sucesos se acuerda crear una comisión que proponga a la Cámara "un plan general".

El dictamen en cuestión da lugar a un fuerte debate toda vez que el mensaje de aquel no es alentador:

La Nación española se encuentra en una ocasión muy crítica, y no hay circunstancia alguna, por pequeña y aislada que parezca, que no puede influir eficazmente para salvarla de la guerra civil, que es el más horrible de los males ${ }^{67}$.

El debate da lugar a un abierto enfrentamiento entre una parte de los exaltados y la minoria moderada en el que aflora un conflicto constitucional potencial: mientras que los primeros sostienen posiciones favorables a una interpretación de la Constitución en el sentido de la primacía general e incondicionada de las Cortes, los segundos la rechazan porque la misma es una "doctrina enemiga de la libertad" en cuanto que desconoce la división de poderes. Por el contrario recibe general asentimiento el juicio de Alix que subraya que la coincidencia de incidentes que afectan a unidades militares en Pamplona, Valencia, Barcelona y Murcia sugiere unidad de propósito y planificación. Si bien Seoane trata de dar una nota algo menos pesimista en razón de la dificultad de la insurgencia de controlar el territorio:

Es verdad que no hay ninguna provincia, a excepción de la desgraciadísima Navarra, que presente sintomas declarados de rebelión; es verdad que afortunadamente en ninguna se desobedece al Gobierno; pero no por eso se pueden dejar de reconocer las señales funestas que indican la tenacidad con la que aun maquina el partido desafecto a la Constitución, no sólo en Navarra, sino en otras provincias del Norte, y los tristísimos sucesos que presentan un aspecto contrario, causan una desunión fatal, no sólo en Valencia, sino en casi todas las provincias del mediodía. ${ }^{68}$

Otros diputados son menos complacientes: Alix señala la reproducción de tensiones entre jefes políticos y ayuntamientos en torno a la Milicia, Pacheco

66 Los sucesos rebrotarán en mayo con la sublevación de una parte del regimiento de artilleria aplastada por el resto de la guarnición y la milicia. Vid. DSC, legislatura de 1822, 3/6/1822, pp. 1686 y ss.

67 DSC, Legislatura de 1822, 23/3/1822, p. 492.

68 Loc. cit., p. 505. 
subraya el riesgo de erosión de apoyo del ejército a la Constitución y sostiene la necesidad de potenciar la acción de la Milicia y González Alonso cita ejemplos reiterados de resistencia judicial al cumplimiento de las leyes votadas por las Cortes, con el consiguiente problema de los nombramientos judiciales.

Con todo el problema concreto que más llama la atención es la reproducción de los incidentes en Pamplona, con conflicto abierto entre la guarnición y la Milicia de la ciudad. La respuesta a tan delicada cuestión da lugar a un acalorado e interesante debate ${ }^{69}$ en el que se trasluce la gravedad de la situación. La sublevación pamplonesa ha sido protagonizada por la Milicia, por una Milicia que, desde el principio, dio muestras de "poco afecto al sistema constitucional", tras cuyo descontento se halla la vindicación de los fueros, como señala alguien tan ponderado con Álava:

Es notorio que en esta provincia ha existido por muchos siglos una Constitución propia de aquel país, y que malévolos, tanto nacionales como extranjeros, se han servido de esta circunstancia para crear a los naturales, primero que con la sujeción a la Constitución lo han perdido todo, y segunda que tienen interés en restablecerla a toda costa.

Pero la cuestión no se reduce ni a Pamplona, ni a los fueros, el repertorio realista es más amplio y tiene audiencia social. Setién es claro:

...y empezaré desde noviembre ultimo en que pulularon por toda la Peninsula las conmociones y sublevaciones que, aun siendo parciales, casi llegan a ponerse en contacto los unos con los otros. A mitad de noviembre del año último estaba ya en combustión casi toda la Península (citas de Cataluña y Aragón).

Lo que implica que las Cortes se enfrentan no ante una serie de actuaciones subversivas puntuales, sino ante una operación planeada y que usa un repertorio de temas politicos plural al efecto de alimentar la subversión:

Se sabe el sistema de nuestros enemigos, que tienen una táctica muy final, muy perspicaz y muy maligna. Vemos como halagan y engañan a los pueblos, valiéndose de sus propias preocupaciones; a unos por los fueros, a otros por la religión, a otros por las contribuciones para que odien la Constitución, se cansen de ella y se subleven y asesinen a las autoridades constitucionales, y tengan la osadía de romper lápidas.

Así pues el realismo se alimenta de tres fuentes internas: la nostalgia fuerista, la defensa de una religión que se entiende atacada y la fatiga fiscal. A ellas cabe agregar, como señala con lucidez Álava, la conducta del gobierno francés, de un ministerio galo formado por lo más granado del legitimismo, para el que la mera presencia de un sistema constitucional basado en el odiado dogma revolucionario de la soberanía nacional es percibido como un riesgo existencial:

Es preciso decirlo francamente, Señor, mientras el Ministerio francés este en manos de los que actualmente lo ocupan, será muy dificil que la España constitucional pueda esperar de el seguridad y reposo pero también que llevan hasta el último grado de fanatismo político su odio a la Constitución española me bastaría para juzgarlo el ver la protección y auxilios que se dan en Bayona a todos los conspiradores contra nuestro Gobierno, y ver

${ }^{69}$ DSC, Legislatura de $1822,26 / 3 / 1822$, pp. 566 y ss. 
mantener durante el invierno un ejército que aunque pequeño para inspirar cuidado, sirve para mantener ilusiones y para alimentar esperanzas criminales en una porción de gentes que solo desean el menor apoyo para destruir el actual sistema ${ }^{70}$.

Y que vería con buenos ojos la introducción de un sistema constitucional basado en el principio monárquico, lo que contaría con algún apoyo en el interior, como señala Joaquín Ferrer. La solución adoptada al problema pamplonés pone implicitamente en cuestión algunos de los valores entendidos sobre los que el sistema constitucional se basa: la Cámara acuerda el desarme de la Milicia ${ }^{71}$.

Entre tanto la situación empeora: la violencia se extiende al País Vasco, en cuyo caso viene alimentada por una presión fiscal producto de la aplicación del sistema general y de la manipulación del reparto de las cargas $^{72}$, y se degrada rápidamente en Cataluña, no sólo por el apoyo masivo a las partidas por parte del clero $^{73}$, sino también por el apoyo que reciben del gobierno galo. Como corresponde a una guerra civil la misma abre la puerta a la querellas y venganzas personales y a la fractura social ${ }^{74}$, empero lo más preocupante no es tanto ese estado de confrontación interna, sino la situación de empate a la que se está llegando: cada parte tiene la capacidad de pelear con éxito en defensa de su proyecto, pero ninguna es tan fuerte que pueda imponerse de modo concluyente. En las palabras de Salvá:

Los facciosos pululan por todas partes, los serviles levantan osados su cabeza en todos los ángulos de la Península, y puede decirse que nos está devastando la guerra civil, guerra que entre nosotros tendrá el carácter más feroz de cuantas han existido, puesto que los diversos partidos son bastante fuertes para destrozarse los unos a los otros, y ninguno lo es tanto que pueda sojuzgar a los demás. ${ }^{75}$

El agravamiento del problema induce a una parte creciente de los diputados a poner en cuestión la aplicación del decreto de abril de 1821, ya visto, toda vez que la práctica de indultar a los facciosos que se sometan surte un efecto perverso: si el alzado fracasa se acoge al indulto y hasta la próxima oportunidad. Comienza a hacer acto de presencia la demanda de una legislación de excepción.

La tentación exaltada tiene como primera muestra el intento de control parlamentario directo de la Milicia. Con motivo del debate sobre la ordenanza de la Milicia Nacional, a la que se le atribuye la doble misión de cuidar del orden público y sostener al régimen (vide arts. 62 y ss.) se propone la creación de una

70 Vid. Barabe, N. "Diez años de la Constitución de Cádiz en el debate político francés”, Historia Constitucional, $\mathrm{n}^{\circ} 13,2012$, pp.36 y ss, especialmente pp. 46 y ss.

71 Loc. cit., p. 579.

72 Torre, DSC, Legislatura de 1822, 1/5/1822, p. 1111.

73 "Según lo que yo he visto en la provincia de Cataluña, los curas párrocos, los Obispos y demás Prelados, casi en su totalidad de una u otra clase están en contradicción con el sistema". DSC, Legislatura de 1822, 15/5/1822, p. 1367.

74 "Han procurado y logrado extraviar la opinión pública hasta el punto de envolver aquella provincia en la guerra civil, de ir pueblos contra pueblos, padres contra hijos e hijos contra padres". Loc. cit., p. 1396.

75 DSC, Legislatura de 1822, 15/5/1822, p. 1369. 
comisión de cinco diputados para dirigirla, es decir los exaltados quieren hacerse con el mando directo de toda la Milicia. Dicha medida, de inconstitucionalidad paladina, suscita una oposición general, incluso entre la propia mayoría exaltada, por demás bien poco cohesionada, como recuerda Alcalá Galiano, y la propuesta, muy combatida, en especial por Argüelles, es rechazada. ${ }^{76}$

En el ínterin la comisión formada para examinar la problemática de la seguridad pública presenta su dictamen ${ }^{77}$. El dictamen señala que hay un marcado contraste entre la actitud de la nobleza y la del clero respecto al sistema constitucional: mientras que la primera apoya mayoritariamente el régimen, el clero presenta un panorama muy distinto: el bajo clero es sedicioso y la jerarquía es cómplice por pasividad o silencio. El influjo del clero se entiende consecuencia de la falta de instrucción de la mayoría de la población (aunque no se llega a decir expresamente se trasluce que se habla del campesinado), lo que exige llevar la enseñanza a todas partes al efecto de llevar la ilustración al campo.

El eje del problema de la seguridad no obstante, no es tanto el descontento potencial o la oposición política, es mas bien la creciente fractura social que lleva al país por el camino que conduce a la guerra civil, fractura y tendencia cuyos partidarios se están dotando de organización:

El Estado de la Nación es crítico y peligroso: en ella no esta formado convenientemente el espíritu público; existe una grave división de opiniones que, agitando fuertemente las pasiones en encontrados partidos $\mathrm{y}$ exasperándolo de día en día, no ya compromete el peligro de guerra civil, sino que empieza desplegar sus estandartes; y al mismo tiempo que reina en el interior esta fatal disposición, se advierte, a no poder dudarse, que se va formando una coalición poderosa contra el sistema constitucional.

Se aprecian dos clases de desórdenes: de un lado las que suponen desconfianza en el Gobierno (en el momento todavía moderado, su cabeza es Martínez de la Rosa), y defienden la adopción de medidas radicales para hacer frente a la subversión ("reclaman el castigo de los conspiradores"), citándose al efecto Cádiz, Sevilla, Granada, Málaga, Jaén, Córdoba, Murcia, Badajoz, Barcelona, Coruña, Valencia, Madrid, Zaragoza "y algún otro". En otras palabras la alteraciones del orden y la seguridad que traen causa de la división entre los constitucionales. De otro lado la de quienes imputan a los liberales republicanismo e irreligión y suponen "pronunciamientos contra la Constitución", cuyo repertorio no es ciertamente breve:

Aragón: Caspe, Tarazona, Pina, Huesca, Calatayud, Alcañiz "y otros".

Navarra: "muchos de la provincia de Navarra, especialmente su capital".

Cataluña y Valencia: algunos "sobre todo en Orihuela".

Extremadura: Plasencia, Coria, Trujillo.

La Mancha: Ciudad Real, Almagro, Miguelturra.

Andalucía: Lucena.

Castilla y León: “algunos de la provincia de León", Palencia, Zamora, Toro, Daza, San Leonardo, Osma, el Burgo y Fuenmayor en Soria.

Galicia: Orense.

76 DSC, Legislatura de 1822, 23/6/1822, p. 2105.

77 DSC, Legislatura de 1822, 15/6/1822, p. 1925 y ss. 
Mientras que en las primeras el protagonismo corresponde primariamente a los milicianos, y parcialmente, a la tropa, las segundas son obra primaria del pueblo bajo:

En las agitaciones del primer sentido han tomado parte las Milicias locales y algunas veces cuerpos de guarnición; y en las segundas, las partes del pueblo de menos significación entre las clases de la sociedad.

Donde comienza a apuntar el foso entre clases populares y burguesía que caracterizará la politica nacional cuanto menos hasta bien entrada la Restauración.

La comisión propone medidas de supervisión de las opiniones políticas del clero, que se aprueban ${ }^{78}$, y significativamente propone se prohíba la venta libre de pólvora y plomo en

...las provincias vascongadas, Navarra, Zaragoza, Huesca, Teruel, Calatayud, Lérida, Tarragona, Gerona y Barcelona.

Buena geografía del núcleo principal de la oposición armada. Por cierto la prohibición se aprueba. Del mismo modo que se propone nada menos que declarar "fuera de la ley" a "los pueblos en donde se auxilie y ampare a los facciosos".

Y hacen acto de presencia algunos de los problemas estructurales, como la problemática fiabilidad de buena parte de la magistratura, o el más espinoso: siendo la Milicia el principal responsable del orden público y depender la misma de la autoridad local ¿qué hacer para evitar el riesgo de captura de aquellas por el adversario?

Consta a la Nación entera que hay muchos pueblos en donde no podemos lisonjearnos de que el espíritu público de sus habitantes pueda presentarnos la garantía necesaria para conceder a los Ayuntamientos el mando de esta fuerza, que siendo protectora de la libertad pública y uno de los más firmes apoyos de la Constitución, debemos tratar de que no pueda introducirse en ella un mal espíritu. ${ }^{79}$

Y en eso llegó el golpe de Estado de julio de $1822^{80}$. La sublevación de la Guardia Real tiene lugar cuando el parlamento está cerrado, empero si las Cortes están en vacación la Diputación Permanente permanece, y esta no va a estar precisamente pasiva, apenas producida la sublevación, el día dos de julio, la Diputación dirige un mensaje al rey advirtiéndole de que si el monarca no toma medidas para poner fin a aquella, la Diputación se verá obligada a tomarlas. La comunicación se reitera, de tal modo que la Diputación, previo dictamen del Consejo de Estado, comunica el día 6 al rey que si este no da las órdenes,

La diputación, en cumplimiento de sus deberes, no puede dejar de poner en ejecución cuantos recursos estén a su alcance dentro de los límites de sus actuaciones

78 DSC, Legislatura de 1822, 18/6/1822, p. 1992 y ss., y 19/6/1822, pp. 2011 y ss.

79 Romero, DSC, Legislatura de 1822, 25/6/1822, p. 2144.

80 Vid. La Parra, E. Fernando VII. Un rey deseado y detestado, Tusquets, Barcelona, 2018, pp. 411 y ss. 
El día 7 la Diputación comunica al rey que o bien se coloca "en términos de ser custodiado por tropas fieles" o bien la Diputación actuará:

Se vería precisada, sin pasar de hoy, a convocar Cortes extraordinarias y entregar las riendas del Gobierno a una Regencia.

A tal efecto la Diputación consulta al Consejo de Estado, y esta dictamina que el rey se halla en la situación de "inhabilidad moral" del art.162 de la Constitución. Hay luz verde para proveer una Regencia. ${ }^{81}$

La derrota de la Guardia ese día y el triunfo de la Milicia de Madrid y de las tropas leales hace que no sea necesaria tan drástica medida. Mas allá de guardar las formas, los equivocos que pudieran subsistir en torno a la posición del rey pasan al archivo. La "enfermedad" regia de 1823 tiene aquí su precedente.

\section{EL FRACASO DE LA SUBVERSIÓN INTERNA Y LA INTERVENCIÓN}

El fracaso del golpe de estado de julio de 1822 aborta cualquier proyecto de restauración del absolutismo "desde arriba" y reduce la gama de opciones disponibles a dos, no necesariamente incompatibles: el recurso intensivo a la guerra civil y la intervención de la Santa Alianza. La primera línea de acción exige la extensión de la guerra de partidas al conjunto del territorio, que dé lugar al surgimiento de una o varias "áreas liberadas" donde instalar una administración realista que, a su vez, permita pasar del estadio de la guerrilla a la guerra abierta entre formaciones militares, entre ejércitos más o menos formales. Crear por la fuerza una suerte de contra-Estado realista con capacidad para competir militarmente con el aparato estatal existente, controlado por los liberales, al efecto de desplazarlo primero y destruirlo después, bien sea con la cooperación activa de las monarquías, bien sea con su apoyo político y financiero. Por ello no debe extrañar que el verano de 1822 vea un recrudecimiento de la guerra de partidas y de su extensión, que crezca el apoyo material francés, que se intente crear alguna "zona liberada" a partir de la cual montar el contra-Estado realista, caso en el que la realidad otorga un rol capital al establecimiento de la "Regencia de Urgell" tras caer dicha fortaleza en manos absolutista e instalarse allí (cuanto menos pro-forma) una autoridad formal rival del gobierno constitucional.

Convocadas Cortes Extraordinarias, cuando estas se abren el 8 de octubre el panorama es bien oscuro desde la perspectiva liberal: el Estado constitucional está perdiendo el control del territorio y el riesgo de una administración rival deja de ser un riesgo hipotético para pasar a ser una realidad en construcción. Resulta obvio que los recursos empleados hasta la fecha no son suficientes para asegurar la primacía del Estado y, con ella, la del régimen constitucional. No debe extrañar que el mensaje del rey con el que se abren las Cortes reclame un esfuerzo,

para proporcionar recursos al Gobierno, tanto en hombres como en dinero, para hacer frente a las urgentes necesidades del estado, y desembarazar a la nación de las bandas facciosas que infestan sus provincias fronterizas. ${ }^{82}$

${ }^{81}$ Recuérdese que en el sistema gaditano la Regencia es siempre parlamentaria (art.192 de la Constitución) según la tradición castellana. Una regencia puramente legítima no aparecerá hasta la reforma de 1845 (de donde procede por cierto buena parte del T.II de la constitución vigente, a través del texto de 1876). 
Al efecto el día 13 el secretario de Guerra (y no el de Gobernación de la Península) lee la correspondiente memoria y abre un debate sobre la situación toda vez que los medios hasta entonces empleados no resultan suficientes para hacer frente a la situación:

Dos grandes y tristes verdades arroja de si la citada Memoria: primera que la insurrección de aquellas provincias ha tomado alguna consistencia, y que su carácter es de tal naturaleza, que debe llamar muy particularmente la atención de las Cortes y del Gobierno; segunda, que los medios de pacificación que se han empleado hasta ahora son insuficientes, y de aquí la necesidad de auxiliar al Gobierno con nuevos recursos ${ }^{83}$

Se señalan como explicación de la situación tres concausas: una de ellas de origen externo, las otras dos de origen interior. La primera es el apoyo activo del gobierno francés que financia, sostiene y equipa a las guerrillas (y que es la razón por la que el centro de la lucha se sitúa en las provincias de la frontera pirenaica), la segunda, la penuria de la población, sobre la que recaen una coyuntura económica desfavorable, las consecuencias de la quiebra de la seguridad y el aumento de la presión fiscal, la tercera la actividad facciosa del clero, al extremo de sostener y difundir un discurso de cruzada:

... y que, por consiguiente la guerra declarada a los liberales es una guerra santa, y los asesinatos, los robos y las otras tantas obras meritorias para ganar la vida eterna.

El gobierno solicita las tres cosas urgentes: la primera de ellas es obvia, al ser el presupuesto de las otras dos, a saber: dinero. Sin un aumento de los ingresos no es posible sostener lo que ya es una guerra, irregular, pero guerra; la segunda es ampliar la autorización del uso de la Milicia fuera de sus provincia más allá de los 20.000 efectivos que en el momento se hallaban autorizados; finalmente reemplazos tanto para la milicia como para el ejército, que se estiman necesarios, nada menos que un incremento del $60 \%$ de la fuerza estimada para tiempos de paz, y que se cifra in concreto: 29.973 hombres y 7.693 caballos. La oficialización de la guerra civil ${ }^{84}$.

Por su parte el ministro de la Gobernación agrega que el problema es especialmente en Cataluña:

Pero ni tomando en consideración la extensión de la Península, y la diversidad de sintomas de conspiraciones que más o menos gravemente se han manifestado en varias partes, y que el Gobierno no ha podido sofocar no teniendo medios suficientes para contener de un modo importante a los conspiradores. Cataluña es la provincia en que la sublevación ha tomado alguna más consistencia, y así es que el Gobierno ha procurado reunir en ella la mayor fuerza posible para sofocarla; pero las demás provincias necesitan igualmente una fuerza de tropas que contenga a los conspiradores. 85

\footnotetext{
82 DSC, Cortes Extraordinarias 1822/23, 8/10/22, p. 21.

83 DSC, Cortes extraordinarias 1822/23, 13/10/22, p. 154.

$84 \mathrm{El}$ correspondiente proyecto de ley se presenta el 20 de octubre.

85 Loc. cit., p. 157.
} 
El debate, breve, parte de la constatación de que la guerra civil es un hecho, $\mathrm{y}$ que esta surgiendo frente a la fuerza armada del Estado una alternativa del realismo.

Nuestra existencia civil, que es el segundo objeto de la fuerza armada... se halla en peligro y atacada, y por provincias que están insurreccionadas con tropa armada. 86

No hace falta invocar a la Regencia de la Seo. No tiene nada de sorprendente que, enfrentados a una crisis de estado la propuesta se adopte por unanimidad. Ahora bien, el mero recurso a la fuerza militar no basta, si de derrotar la insurrección se trata. A este efecto, y a través de una comisión, la mayoría exaltada va a desgranar una serie de propuestas que ocuparán buena parte del tiempo parlamentario hasta enero de 1823. En apretado resumen estas pueden resumirse así:

Primera. Formar y aplicar un reglamento de policía, al efecto de poder tener un control efectivo de la población.

Segunda. Privación de oficios al clero disidente y habilitación al Gobierno para detener y confinar religiosos.

Tercera. Facilitar al Gobierno el traslado forzoso de empleados públicos.

Cuarta. Sancionar económicamente a los pueblos que no ofrezcan resistencia a las partidas.

Quinta. Habilitar a los jefes militares para imponer exacciones y multas a las autoridades civiles hostiles o reticentes.

Sexta. Habilitar al Gobierno para suspender ayuntamientos.

Séptima. Hacer uso de derecho de excepción previsto en el art.308 de la Constitución.

Octava. Introducir la responsabilidad civil mancomunada por los daños causados por las partidas.

Novena. Revisar los nombramientos judiciales al efecto de prescindir de los jueces de lealtad dudosa.

Décima. Hacer factible la depuración de la oficialidad y mandos del ejército.

Undécima. Extinción de los conventos desde los que se conspire.

Todo un programa, y bien severo ciertamente.

La primera pieza es la formación de un reglamento de policía que articule un sistema que haga posible el control de la población. La propuesta que la comisión presenta el 16 de octubre 87 contiene cinco reformas: en primer lugar la implantación de un pasaporte interior necesario para viajar por el territorio nacional y, como corolario, la necesidad de notificar a la autoridad sirvientes y visitas; en segundo lugar, realizar una matrícula detallada de la población; en tercer lugar, organizar el espacio: establecimiento de un padrón, subdividir los pueblos en barrios con numeración de viviendas y habilitación para crear delegados de barrio; finalmente crear "partidas de seguridad" para hacer frente tanto al desorden como al bandidaje.

86 Loc. cit., Setién, p. 159, en el mismo sentido Soria, p. 160.

87 DSC, Cortes Extraordinarias 1822/23, 16/10/1822, p. 188. 
El proyecto del reglamento general de policía se presenta el 20 de noviembre y desarrolla aquellas propuestas especificando que el pasaporte interior debe ser visado en todos y cada uno de los pueblos del itinerario del viaje y señalando que, además de encomendar la custodia de los caminos al ejército y la milicia, se haga posible el establecimiento de "partidas de escopeteros" para vigilar los caminos ${ }^{88}$, como veremos.

Con todo el problema al que se da prioridad es a la cuestión del clero. La propuesta de la comisión no es moderada: se trata de habilitar al gobierno no sólo para proceder a la privación de oficios a los clérigos sospechosos, sino también para confinar o desterrar a los clérigos disidentes, aun cuando una parte de los moderados señala la inconstitucionalidad de la medida, se impone el criterio de la comisión porque, como dice Alcalá Galiano:

Una guerra intestina esta desolando muchas provincias... las demás, digo, se ven amenazadas por las maquinaciones sordas que tienen por origen principal el clero, el cual, por una desgracia que vemos y no podemos contener, ha creído que debía oponerse a la regeneración política de la Nación, a pesar de que conoce que afianza la religión como las leyes anteriores. ${ }^{89}$

"Que vemos y no podemos contener", no se puede ser más claro. Ahora bien la medida adoptada afecta sólo al clero secular, siendo más serio el problema del clero regular. La respuesta es simple: constatando que los conventos que en mayor medida respaldan la insurrección son aquellos que se hallan en el campo, toda vez que aquellos que se hallan en entorno urbano el medio es más favorable a los constitucionales y las posibilidades de control son mayores, se plantea pura, lisa y llanamente la extinción de todos los conventos que se hallen en "despoblado":

Está en cierto modo demostrado que en algunos conventos de religiosos conspiran, seducen y facilitan medios y recursos para perjudicar a la nación; pero se ha observado, y se tuvo presente en la legislación anterior, que este mal, donde produce sus efectos, era en los conventos que se hallan en despoblado. En estos, y en los de las poblaciones pequeñas tienen más medios de hacer daño y las autoridades locales menos medios de evitarlo. ${ }^{90}$

A algunos exaltados la medida les parece corta $^{91}$, pese a ello, y a la vista de las dificultades de proceder a una extinción completa (claramente impolitica en el momento), se acuerda aprobar la propuesta de extinción parcial planteada por la comisión: se suprimen los conventos en despoblado y se redistribuirán sus frailes entre los urbanos. Para estos últimos, tiempo habrá.

Muy distinto es el problema de los empleados públicos toda vez que en la época se asumía que la plena disponibilidad sobre el empleo era condición necesaria para poder exigir responsabilidad a los gobernantes: el poder ejecutivo no puede ser responsable si no dispone libremente de los empleos para proveerlo

88 DSC, Cortes Extraordinarias 1822/23, 20/11/1822, pp. 689 y ss.

89 DSC, Cortes Extraordinarias 1822/23, 20/10/1822. Alcalá, p. 243, alegaciones de inconstitucionalidad por Prado y Munarriz, p. 248, aprobación p. 249.

90 Oliver, DSC, Cortes Extraordinarias 1822/23, 25/10/1822, p. 330.

91 Alix, loc. cit., p. 331, en contra Prado, p. 331-3. 
de personal de confianza. La propuesta de la comisión está diseñada para ampliar el margen de discrecionalidad: el gobierno quedaria habilitado para trasladar a su arbitrio a cualquier empleado, la razón subyacente es sencilla: hay empleados públicos dotados de título que no pueden ser separados del servicio público sino mediante expediente $\mathrm{y}$, en su caso resolución judicial, paradigmáticamente los oficiales de los cuerpos facultativos. De lo que se trata es de flexibilizar el régimen de los empleados según el criterio "el que paga, manda". Argüelles es muy claro al respecto:

Toda persona que tiene sueldo del Gobierno, pensión o que con cualquier denominación que sea, disfruta del Erario público alguna asignación, mientras la disfrute es una penalidad consiguiente a ese goce el que esté al arbitrio del Gobierno para ser trasladado donde este crea más conveniente.

No es la posición más radical, hay quien sugiere que el traslado forzoso se de aun cuando el empleado renuncie, a la postre el 21 de octubre la propuesta se adopta. ${ }^{92}$

Distinto es el destino de la propuesta de sancionar a los pueblos que no se oponen a los "facciosos". Aquí pese al empeño de la mayoría exaltada de sacar adelante la medida, aquella viene a estrellarse al topar con la realidad: se trata de una medida que, a más de impopular, resulta sencillamente inaplicable, en consecuencia la misma no es aprobada por las Cortes ${ }^{93}$. No por eso cesa la presión de la mayoria, el 24 de octubre vuelve la cuestión, con otro formato: exigir responsabilidad civil por los daños causados por los insurgentes. La propuesta suscita fuertes críticas por afectar directamente al derecho de propiedad, empero llega a ser aprobada, bien que modificada: se podrá exigir una responsabilidad civil mancomunada por daños. Pero exigirá previa formación de causa. ${ }^{94}$

Probablemente las medidas más importantes, de entre las propuestas, son aquellas que van derechas al fondo del problema: si las partidas pueden actuar en el modo en que lo hacen se debe a que cuentan con apoyo popular y la complicidad, cuanto menos, de las autoridades locales. De este modo el instituto del ayuntamiento constitucional se vuelve contra sus creadores. No sin exceso de retórica apunta Alcalá Galiano:

El olvido de sus más sagrados deberes ha llegado hasta lo sumo en las autoridades municipales. Puestos por los pueblos para velar por su seguridad, han sido muchos de ellos parricidas, ocultando y protegiendo a los facciosos. Ellos han sido la causa de que varias columnas del ejército hayan sido cortadas o sorprendidas. ${ }^{95}$

Al efecto se vienen a proponer dos cosas: la primera, habilitar a las autoridades militares para sancionar económicamente a los municipios refractarios; la segunda, habilitar al gobierno para suspender ayuntamientos. Las medidas son ciertamente rigurosas, pero no despiertan la unanimidad en las Cortes precisamente, entre otras razones porque el desarrollo de las operaciones

92 DSC, Cortes extraordinarias 1822/23, 21/10/1822, Argüelles, p. 258. Vid. Falcó, pp. 261-62, admisión expresa de ser medida de excepción Alcalá Galiano p. 259. Aprobación p. 267.

93 Loc. cit., p. 268.

94 DSC, Cortes extraordinarias 1822/23, 24/10/1822, p. 314.

95 Loc. cit., p. 274. 
es tal que la balanza se está inclinando lenta, pero constantemente, del lado de la causa liberal, que se beneficia, entre otras cosas, del cansancio que produce una guerra civil en la que los excesos son más bien la regla que la excepción. Por ello Soto puede argumentar al efecto de moderar el rigor que,

Además, según las cartas particulares, los periódicos y nuestras mismas conversaciones, una de las cosas que contribuyen a hacernos esperar el triunfo de la buena causa, es la multitud de excesos que comúnmente cometen los facciosos, siendo demasiado gravosos a los pueblos, y ninguna cosa perjudica más a la causa de la libertad que las medidas de excesivo rigor. ${ }^{96}$

Además, la propuesta tiene el defecto, serio y grave, de abrir la puerta a la arbitrariedad. Como consecuencia, la propuesta no es aceptada y se acuerda vuelva a la comisión ${ }^{97}$. No obstante, retorna levemente modificada al día siguiente y la propuesta acaba por aprobarse ${ }^{98}$, pese a la objeción de que ello supondría establecer el estado de guerra en el municipio. 99

Más radical es la propuesta de habilitar al gobierno para suspender ayuntamientos. Esta ofrece base suficiente a las dudas de inconstitucionalidad, de un lado porque no existe para ello habilitación constitucional clara, del otro porque supone dar al gobierno facultades que deberian residir en las Cortes. No debe extrañar que los moderados se opongan alegando que su adopción supone dejar en manos del ejecutivo la voluntad del pueblo ${ }^{100}$, empero la realidad es la que es y esta indica que no son pocos los casos en los que las partidas pueden operar por la connivencia de las autoridades locales:

Hemos visto a un Zaldivar, a un Merino, a un Rojo de Valderos estar ocultos en los pueblos y volver a aparecer después de algún tiempo ¿Cómo habrían de estar ocultos sino por la connivencia de las autoridades, que tienen interés en ocultarlos a la vista de las tropas constitucionales? ${ }^{101}$

La propuesta es adoptada.

Otra cosa sucede con la de activar el supuesto de medida excepcional previsto en el art.308 de la Constitución. De entrada la comisión propone su extensión a todo el territorio nacional, lo que supone, obviamente, levantar las restricciones que la Constitución impone en orden a las garantias de la puesta en custodia. Si la insurrección fuere materialmente generalizada no cabe duda de que la medida aparecería como razonable, pero aquella generalización no se da en la realidad: mientras hay provincias en las que la guerra civil es una realidad cuotidiana hay otras en las que tal situación no se produce. Ello da pie a la oposición de los moderados, que se centra en exigir, de un lado, que la medida sólo se aplique a las provincias "en insurrección” y del otro que se especifiquen

96 Loc. cit., p. 269.

97 Loc. cit., p. 271.

98 DSC, Cortes Extraordinarias 1822/23, 22/10/1822, p. 277.

99 Oliver: "Ha dicho el sr. Munárriz que esto viene a ser declarar el estado de guerra a esos pueblos a los que se sujeta a las autoridades militares. A esto ha respondido igualmente el sr, Ruiz de la Vega: el pueblo en cuyo distrito hay facciones, se halla en estado de guerra". Loc. cit., p. 277.

100 Ad ex. Argüelles, loc. cit., pp. 281 y s.

101 Oliver, loc. cit., p. 280. 
las autoridades habilitadas para proceder a la puesta en custodia y el procedimiento a seguir. Tras un debate muy empeñado en el que el protagonismo recae en Argüelles, por un lado y en Alcalá Galiano por el otro ${ }^{102}$, la propuesta de la comisión es rechazada por la Cámara. No obstante los exaltados no se rinden y el 31 de octubre traen al debate un proyecto ${ }^{103}$ en el que se previene, de un lado, se pueda detener a un ciudadano sin las garantías previstas en la ley fundamental, comunicando al reo las razones dentro de las siguientes 48 horas a contar desde la privación de libertad, tras lo cual se abre un plazo de 30 dias que concluye bien con la puesta en libertad, bien en la puesta a disposición de la persona del detenido a la autoridad judicial; del otro se prevé la suspensión de la inviolabilidad del domicilio por orden del jefe político o sus delegados, suspensión que, en principio, comprende a todos, incluidos los diputados. Finalmente, estas medidas vivirian lo que las Cortes Extraordinarias, caducando con su extinción.

Los términos del debate acreditan la demonización de la oposición armada: los realistas son "los malvados" (Canga Argüelles), son "indignos de todo respeto humano" (Falcó) o los que siguen "vertiendo sobre nosotros la negra copa de su veneno". Ahora bien, el proyecto genera una intensa oposición no sólo porque es claramente inconstitucional ${ }^{104}$, sino también porque al comprender a los diputados afecta directamente tanto a su inviolabilidad como a su aforamiento ${ }^{105}$. La afectación de los diputados así como la de los diplomáticos acreditados prolongará el debate hasta mediados de noviembre, siendo aprobado al precio de excluir de su ámbito de aplicación tanto a unos como a otros.

Quedan las cuestiones sobre el personal público, en especial jueces y militares profesionales, que se tratan los dias 24 y 25 de octubre. Respecto de la magistratura la comisión propone se acuerde una suerte de depuración general, bajo la forma de una revisión gubernativa de los expedientes de los nombramientos judiciales que apruebe el Consejo de Estado (como previene la Constitución), al efecto de eliminar a los "jueces prevaricadores". Istúriz es claro en punto a finalidad:

Es necesario que SS y el Congreso sepan que los objetos principales de la comisión al indicar esta medida son dos. Primero, hacer desaparecer todos los jueces que por sus ideas e intereses no sólo no favorecen al sistema, no sólo lo contrarian, sino que favorecen la rebelión. 106

Por boca de Argüelles los moderados se oponen, cuanto menos por dos razones: de un lado porque la propuesta es inconstitucional; del otro porque en

102 DSC, Cortes Extraordinarias 1822/23, 23/10/1822. Argüelles, pp. 291 y ss. Alcalá Galiano, pp. 295 y ss.

103 DSC, Cortes Extraordinarias 1822/23, 31/10/1822, pp. 409-10.

104 Alcalá Galiano lo reconoce abiertamente: se trata de arrestos fuera de lo previsto por la Constitución y producidos en base a la "certeza moral". Vid. DSC, Cortes Extraordinarias 1822/1823, 31/10/1822, p. 422. Por cierto que recurriendo a la distinción rousseauniana entre ley y decreto se llegó a discutir si se trataba de una cosa u otra, no era accidental, si se trataba de una ley debía pasar a la sanción regia, que es lo que se acordó. DSC, loc. cit., 16/11/1822, pp. 643-44.

105 En el sistema doceañista los diputados sólo pueden ser juzgados por sus pares mediante el Tribunal de Cortes, y es a este al que competen, en su caso, las medidas cautelares a que haya lugar.

106 Istúriz, loc. cit., p. 316. 
todo caso, de haber revisión de los nombramientos judiciales, la misma no debía estar en manos del gobierno, sino en las de las Cortes ${ }^{107}$. Pese a esa oposición, como no se ofrece alternativa para hacer frente a un problema real, la propuesta resulta aprobada. 108

Algo similar se produce respecto de los militares. La comisión propone que el Gobierno pueda trasladar, pasar a la reserva o retirar a los mandos del ejército y (significativamente) de la Milicia Nacional. En el curso del debate, esta vez breve, se admite explícitamente que su adopción hace posible una purga del cuerpo de oficiales, ya que implica que se les pueden retirar los despachos sin necesidad de formación de causa, con todo y pese a ser una cuestión de segundo orden (la mayoría de los mandos de ejército y milicia merecen confianza política), se aprueba. 109

El conjunto de medidas extraordinarias (y provisionales, como se anotó) es entendible en un contexto de guerra civil, cuanto menos parcial, como respuesta a un problema estructural: los instrumentos normales no permiten hacer frente a una crisis existencial, se trata pues de medidas de "salvación pública". Oliver lo dirá con toda claridad:

Se trata, pues, de remediar los males de aquellas provincias en que se sabe que hay tramas ocultas y enemigos del sistema que están suministrando a los facciosos armas y fondos sin ser descubiertos ni poderlos sujetar, porque no hay testigos, ni pruebas para perseguirlos judicialmente. ${ }^{110}$

Dificilmente se puede manifestar mejor el problema que trae causa de la carencia de una eficiente policía que el recuerdo del gobierno intruso impide adoptar.

Con todo, la presión va aflojando y, con cuentagotas, las noticias positivas van llegando a las Cortes. Incluso en Cataluña, en la que la insurrección tiene amplia base y tiene fácil acceso a los fondos, armas y equipos que facilita el gobierno francés, el ejército está ganando la partida. Por citar un solo dato: el mismo día que Argüelles se lamenta de la necesidad de adoptar medidas "que yo no se si hubiera podido preverse que podía llegar una época en que se creyeran necesarias", se da noticia de la derrota de Merino y de la recuperación por Mina de Castellfullit. 111 Unos dias después el secretario de Gobernación de la Península presenta a las Cortes un informe donde se hace eco de la mejora de la situación. ${ }^{112}$

Para ser exactos, lo que esta cambiando en beneficio de la causa constitucional no es tanto la disminución de la inseguridad que causa la combinación entre bandidismo y guerrilla, cuanto otra cosa: a lo largo de 1822 se pone en acción una estrategia de erección de un contra-Estado con capacidad para privar a los constitucionales del control efectivo de al menos una parte del

\footnotetext{
107 Loc. cit., pp. 314 y ss.

108 Loc. cit., p. 319.

109 La propuesta en loc. cit., p. 221, la adopción ídem. 25/10/1822, p. 329.

110 Oliver, DSC, Cortes extraordinarias 1822/23, 1/11/1822, p. 438.

111 Vid. DSC, Cortes extraordinarias 3/11/1822. Argüelles, p. 461, informe p. 465.

112 DSC, Cortes extraordinarias 1822/23, 22/12/1822, p. 1095.
} 
territorio, al efecto de crear una o varias "zonas liberadas" en las que el control del territorio, la población y sus recursos pasa a manos de autoridades realistas para que estas, a su vez, cuenten con la posibilidad de una organización unitaria con capacidad para organizar un ejército alternativo. El logro mayor de esa estrategia es obtener el control de una parte del territorio catalán, ocupar la fortaleza de la Seo de Urgell, y establecer alli una regencia, embrión de un gobierno absolutista. Control del territorio y gobierno alternativo. Pues bien la acción militar de ejército y milicia están consiguiendo abortar ese proyecto: el territorio controlado por la guerrilla esta disminuyendo, el embrionario gobierno realista no funciona, y la recuperación de su sede se halla en el horizonte ${ }^{113}$. La causa constitucional está ganando la guerra civil. ${ }^{114}$

En términos militares las partidas cuentan con unos efectivos más bien modestos y, al nutrirse de un territorio y población determinados, están sujetos a los mismos. La contrapartida liberal es la búsqueda y, de ser posible, la destrucción de cada una de estas partidas mediante el empleo de "columnas volantes", que rara vez cuentan con efectivos amplios. Contamos con un ejemplo de la evolución de una de las mayores y más efectivas de dichas partidas: la de Merino. Cuando este se alza, en el otoño de 1820 , consigue unos efectivos de unos 160 hombres (100 infantes y el resto jinetes, dice puntilloso el jefe político de Burgos), el momento álgido de la insurrección, verano/otoño de 1822, sus efectivos han ascendido a 700 hombres (600 infantes y 100 caballos). De apenas una compañía gemela a algo menos de un batallón mixto. En estas condiciones el paso de la guerrilla a la confrontación militar formal es inviable: la insurrección no puede ganar.

Lo dicho explica por qué desde finales de noviembre la preocupación por las partidas desciende rápidamente en las páginas del Diario de Sesiones, y por qué retorna la preocupación por la otra fuente de inseguridad: el bandidismo. La cuestión arranca del debate del reglamento general de policia, de que se ha hecho mención, toda vez que el mismo contiene una previsión sobre la custodia de los caminos, en la que rebrota una propuesta ya adelantada en 1820: la de una policía rural profesional. En el caso, la propuesta reviste la forma de creación de unidades ad hoc, integradas por profesionales, que ahora no se llamarán "miqueletes" o "miñones", sino "cazadores constitucionales"115.

El citado reglamento autoriza a que las diputaciones provinciales, con el acuerdo del jefe político, puedan reclutar y armar unidades para combatir el bandidismo. Bien entendido que en un escenario en el que la distinción entre banda y partida, entre bandido y guerrillero, es porosa los citados cazadores son bifuncionales:

...en todas hay partidas de malhechores, en unas mas y en otras menos, que si al principio se limitan a atacar la libertad individual de los pasajeros,

113 La recuperación aun se hará esperar, las Cortes reciben la noticia por informe del jefe politico de Lérida. DSC, Cortes extraordinarias 1822/23, 8/2/1823, p. 1452.

114 No andaba desencaminado el rey cuando en ya en la primavera de 1822 era escéptico sobre las posibilidades de éxito de la subversión interna. Vid. La Parra, op. cit., p. 410.

115 Interesa notar que las Cortes actúan en este punto a iniciativa ajena: el día 20 de diciembre tienen entrada en la Cámara sendas exposiciones de las diputaciones provinciales de Navarra y Tarragona pidiendo la creación de tal tipo de unidades. Vid. DSC, Cortes extraordinarias 1822/23, 20/12/1822, p. 1073. La cuestión está en el aire. 
después, reuniéndose y toman el carácter de partidas de facciosos: así se ha visto en Andalucia, en Alicante y en otras provincias. ${ }^{116}$

Las razones que aconsejan la creación de esa policía rural profesional traen causa de las deficiencias que, en la práctica, acusa la Milicia Nacional. Así la Milicia está formada por ciudadanos corrientes que, en el mejor de los casos, cuentan con una experiencia y un savoir faire limitados en lo que a combatir el bandolerismo se refiere, se hallan, pues, en desventaja respecto del bandolero, que cuenta con una experiencia de la que el miliciano carece. Además el miliciano, precisamente por ser un ciudadano corriente, se encuentra en posición de vulnerabilidad respecto del bandolero toda vez que este esta en disposición de dañar sus bienes, intereses y familia, a más de sus personas ${ }^{117}$. En pocas palabras, a un especialista debe hacer frente otro especialista. Devuelto el proyecto a la comisión es de nuevo presentado por esta el 15 de enero de 1823, siendo aprobado al día siguiente. ${ }^{118}$

Al comienzo de 1823 la sombra de la intervención es creciente, sin que esa amenaza consiga que la momentánea unidad de los liberales a la hora de rechazar la nota de las potencias, tenga continuidad en el tiempo, no obstante la cuestión no desaparece de las Cortes. Apenas iniciada la legislatura ordinaria de 1823 la diputación guipuzcoana solicita autorización para crear dos compañias de miñones al efecto tanto de combatir el bandidismo, como para operar contra el ejército francés en caso de invasión. ${ }^{119}$ Conforme el riesgo se incrementa la faceta politica de tales unidades se acentúa: el mismo 3 de marzo Gómez Becerra propone a las Cortes se creen partidas de guerrilleros constitucionales. ${ }^{120} \mathrm{E}$ incluso se trabaja en la provisión de oficiales para "guardias constitucionales de infantería"121. En todo caso la ruptura pública entre el rey y las Cortes con motivo del traslado del gobierno a Sevilla la segunda quincena de marzo y la "enfermedad" del rey después, suscitan un conflicto de lealtades que parte la espina dorsal de los constitucionales, tanto en la administración como en el ejército. Desde el traslado forzoso y la incapacitación temporal del Fernando VII no se puede ser partidario de este rey constitucional toda vez que resulta evidente que el monarca es el primer adversario de la Constitución. Desde finales de marzo de 1823 no es posible ser simultáneamente leal a la Constitución y leal al rey. Esa fractura es uno de los factores explicativos de la débil resistencia a una invasión cuando no se contaba con recursos para resistirla.

Fecha de envío / Submission date: 12/02/2020

Fecha de aceptación / Acceptance date: 18/04/2020

116 Ayllón, DSC, Cortes extraordinarias 1822/23, 22/12/1822, p. 1093. En el mismo sentido Escovedo, loc. cit., p. 1092.

117 Vid. Marau, loc. cit., p. 1095.

118 DSC, Cortes extraordinarias 1822/23, 16/01/1823, p. 1342. El decreto se aplicó, ad. exem vide Calles Hernández, C., La Milicia Nacional en Salamanca durante el Trienio liberal. T.D. Salamanca, 2015, pp. 223 y ss.

119 DSC, Cortes de 1823, 3/3/1823, p. 22.

120 Loc. cit., pp. 16-17.

121 Proyecto de reglamento. DSC, Cortes de 1823, 17/3/1823, pp. 87 y ss. 